\title{
Soy Isoflavone Protects Myocardial Ischemia/Reperfusion Injury through Increasing Endothelial Nitric Oxide Synthase and Decreasing Oxidative Stress in Ovariectomized Rats
}

\author{
Yan Tang, ${ }^{1}$ Shuangyue Li, ${ }^{1}$ Ping Zhang, ${ }^{2}$ Jinbiao Zhu, ${ }^{3}$ Guoliang Meng, ${ }^{1,4}$ \\ Liping Xie, ${ }^{1}$ Ying Yu, ${ }^{5}$ Yong Ji, ${ }^{1}$ and Yi Han ${ }^{6}$ \\ ${ }^{1}$ Key Laboratory of Cardiovascular Disease and Molecular Intervention, Nanjing Medical University, Nanjing 210029, China \\ ${ }^{2}$ Department of Gynaecology, The First Public Hospital of Zhangjiagang, Zhangjiagang 215699, China \\ ${ }^{3}$ Aoyang Hospital, Zhangjiagang 215600, China \\ ${ }^{4}$ Department of Pharmacology, School of Pharmacy, Nantong University, Nantong 226001, China \\ ${ }^{5}$ Key Laboratory of Food Safety Research, Institute for Nutritional Sciences, Shanghai Institutes for Biological Sciences, \\ Chinese Academy of Sciences, Shanghai 200031, China \\ ${ }^{6}$ Department of Geriatrics, First Affiliated Hospital of Nanjing Medical University, Nanjing 210029, China
}

Correspondence should be addressed to Yong Ji; yongji@njmu.edu.cn and Yi Han; hanyi79@163.com

Received 16 October 2015; Revised 29 December 2015; Accepted 31 December 2015

Academic Editor: Liang-Jun Yan

Copyright (C) 2016 Yan Tang et al. This is an open access article distributed under the Creative Commons Attribution License, which permits unrestricted use, distribution, and reproduction in any medium, provided the original work is properly cited.

\begin{abstract}
There is a special role for estrogens in preventing and curing cardiovascular disease in women. Soy isoflavone (SI), a soyderived phytoestrogen, has similar chemical structure to endogenous estrogen-estradiol. We investigate to elucidate the protective mechanism of SI on myocardial ischemia/reperfusion (MI/R) injury. Female SD rats underwent bilateral ovariectomy. One week later, rats were randomly divided into several groups, sham ovariectomy (control group), ovariectomy with MI/R, or ovariectomy with sham MI/R. Other ovariectomy rats were given different doses of SI or $17 \beta$-estradiol $\left(\mathrm{E}_{2}\right)$. Four weeks later, they were exposed to 30 minutes of left coronary artery occlusion followed by 6 or 24 hours of reperfusion. SI administration significantly reduced myocardial infarct size and improved left ventricle function and restored endothelium-dependent relaxation function of thoracic aortas after MI/R in ovariectomized rats. SI also decreased serum creatine kinase and lactate dehydrogenase activity, reduced plasma malonaldehyde, and attenuated oxidative stress in the myocardium. Meanwhile, SI increased phosphatidylinositol 3 kinase (PI3K)/Akt/endothelial nitric oxide synthase (eNOS) signal pathway. SI failed to decrease infarct size of hearts with I/R in ovariectomized rats if PI3K was inhibited. Overall, these results indicated that SI protects myocardial ischemia/reperfusion injury in ovariectomized rats through increasing PI3K/Akt/eNOS signal pathway and decreasing oxidative stress.
\end{abstract}

\section{Introduction}

Several researches have demonstrated that there are gender differences in the risk of cardiovascular diseases, such as premenopausal women exhibiting a lower risk than agematched men, but it disappears after menopause [1-3]. It suggests a special role for estrogens in preventing and curing cardiovascular disease in women. As we all know, estrogen replacement therapy (ERT) can attenuate the incidence of cardiovascular events in postmenopausal women [4]. However, several large-scale, randomized, controlled studies have questioned the beneficial effects of ERT in postmenopausal women in many epidemiologic studies [5]. The conflicts have stimulated further research on alternative treatments, such as phytoestrogens. Soy isoflavone (SI), a soy-derived phytoestrogen, is a group of biologically active plant substances with chemical structures which are similar to that of an endogenous estrogen-estradiol [6]. The similarity of structures might partly explain why these compounds have the ability of binding to estrogen receptors (ERs) and exerting various effects.

As the development of thrombolytic therapy or percutaneous coronary intervention in clinic, the incidence of myocardial ischemia/reperfusion (MI/R) injury increases. As 
well as we know, MI/R is an important complication of acute arterial occlusion and subsequent recanalization. Moreover, in the presence of clinical condition, recanalization is used as an attempt to minimize the infarct area; however, the reoxygenation of ischemic heart usually leads to functional loss on the area of myocardial [7-9]. So researchers paid more and more attention to reduce I/R injury. Recently, it is also gradually appreciated that there were distinctions of different gender on sensitivity and/or severity in ischemia/reperfusion (I/R) induced injuries in heart, liver, kidney, and so on $[10,11]$. With consistent findings, females are less susceptible to $\mathrm{I} / \mathrm{R}$ induced injuries compared with males. $17 \beta$-estradiol was reported to protect against myocardial $I / R$ injury in female Wistar rats [12]. Meanwhile, some reports indicated estrogen binding to ER lessened the extent of injury during MI/R after ovariectomy [13]. Previous studies suggested that estrogen receptor mediated protective effect on female $\mathrm{MI} / \mathrm{R}$ injury was associated with phosphatidylinositol 3kinase (PI3K)/protein kinase B (Akt)/endothelial nitric oxide synthase (eNOS) signaling cascade $[14,15]$.

On the other hand, reactive oxygen species (ROS), as highly reactive compounds causing peroxidation of lipids and proteins, play an important role in the pathogenesis of MI/R injury $[16,17]$. ROS have been long-term recognized to enhance oxidative stress and activate $\mathrm{I} \kappa \mathrm{B}$ (inhibitor of NF$\kappa \mathrm{B}) / \mathrm{p}-\mathrm{I} \kappa \mathrm{B} /$ nuclear factor $-\kappa \mathrm{B}(\mathrm{NF}-\kappa \mathrm{B})$ pathway, which was considered as a classic signaling pathway. NF- $\kappa \mathrm{B}$ remains in an inactive state in the cytoplasm in normal station because of a complexing to its inhibitor- $\mathrm{I} \kappa \mathrm{B}$. As response to stress factors, for example, $\mathrm{I} / \mathrm{R}$, different signaling pathways converge on the activation of $\mathrm{I} \kappa \mathrm{B}$ kinase complex (IKK), which induces phosphorylation of the $\mathrm{I} \kappa \mathrm{B}$. Paralleling with the loss of $\mathrm{I} \kappa \mathrm{B}$ in the cytoplasm is the appearance of NF- $\kappa \mathrm{B}$ in the nucleus [18].

Therefore, the purpose of the present study was to determine whether SI protects myocardium from I/R injury through activating $\mathrm{PI} 3 \mathrm{~K} / \mathrm{Akt} / \mathrm{eNOS}$ and reducing oxidative stress pathway. If so, a new ideal would be provided for postmenopausal I/R injury and even other cardiovascular diseases in clinic.

\section{Materials and Methods}

2.1. Animals and Experimental Groups. Animal experiments were conducted according to the Guidelines of Committee for the Care and Use of Laboratory Animals of Nanjing Medical University. Female Sprague Dawley (SD) rats (180 220 g) were obtained from Beijing Vital River Laboratory Animal Technology, Co, Ltd (Beijing, China). Rats were anesthetized with chloral hydrate $(3.5 \mathrm{~mL} / \mathrm{kg}$, intraperitoneal injection) and underwent bilateral ovariectomy (OVX) as previously described [19]. The sham procedure of ovariectomy consisted of administration of anesthesia and visualization of the ovaries through incisions into the abdominal cavity and closure of the wounds.

One week after ovariectomy, the rats were randomly divided into eight groups: sham ovariectomy operation (control group), ovariectomy with sham MI/R (OVS group), or

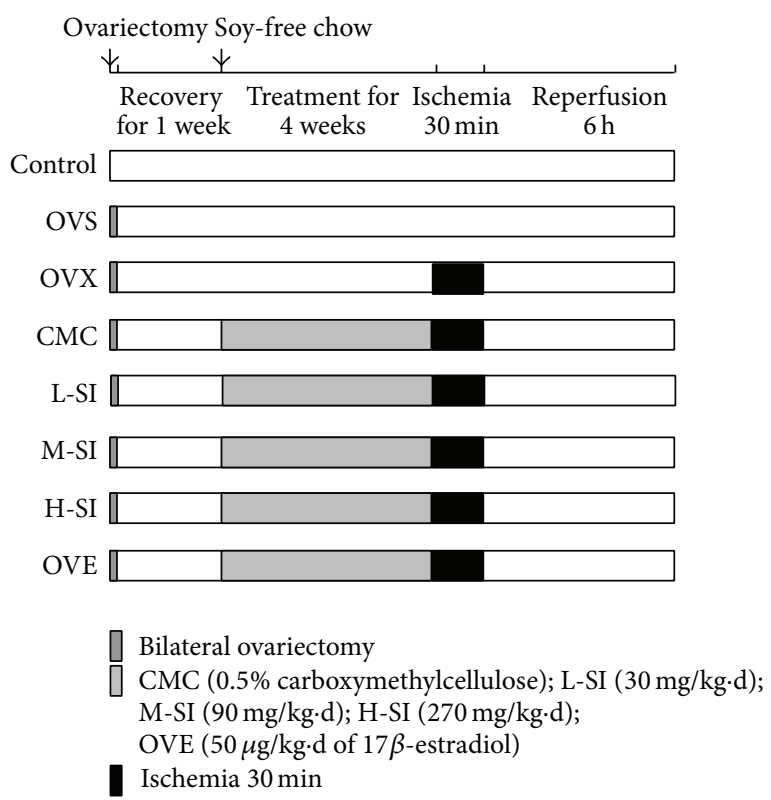

FIGURE 1: Experimental procedure. One week after ovariectomy, rats were maintained with soy free chow and given different treatments. Four weeks later, rats were subjected to $30 \mathrm{~min}$ myocardial ischemia and $6 \mathrm{~h}$ or $24 \mathrm{~h}$ reperfusion.

ovariectomy with MI/R (OVX group). Other ovariectomy rats were given different doses of soy isoflavone (SI) dissolved in $0.5 \%$ carboxymethylcellulose $(\mathrm{CMC}-\mathrm{Na})$ by gavage (LSI group: $30 \mathrm{mg} / \mathrm{kg} \cdot \mathrm{d}, \mathrm{M}-\mathrm{SI}$ group: $90 \mathrm{mg} / \mathrm{kg} \cdot \mathrm{d}, \mathrm{H}-\mathrm{SI}$ group: $270 \mathrm{mg} / \mathrm{kg} \cdot \mathrm{d})$. Additional ovariectomy rats were administrated with the same volume of CMC-Na by gavage (CMC group) or $50 \mu \mathrm{g} / \mathrm{kg} \cdot \mathrm{d}$ of $17 \beta$-estradiol $\left(\mathrm{E}_{2}\right)$ by subcutaneous injection (OVE group) instead of drug once daily over the same period. All rats fed soy-free chow (corn starch: $32 \%$, sucrose: $30 \%$, casein: $23 \%$, corn oil: $5 \%$, cellulose: $5 \%$, mixing mineral salts: $3.5 \%$, mixing vitamin: $1 \%$, DL-methionine $0.3 \%$, and choline dipl-tartrate: $0.2 \%$ ) and water ad libitum. To block the PI3K pathway in vivo, an intraperitoneal injection of a PI3K inhibitor 2-(4-morpholinyl)-8-phenyl1(4H)-benzopyran-4-one hydrochloride (LY294002, SigmaAldrich, MO, USA, diluted in CMC for injection) at dose of $0.3 \mathrm{mg} / \mathrm{kg}$ was given immediately after SI administration.

2.2. Surgical Procedures of $M I / R$. After 4-week treatment, $\mathrm{MI} / \mathrm{R}$ was performed as described previously [20] (Figure 1). All rats except control group were anesthetized with sodium pentobarbital $(40 \mathrm{mg} / \mathrm{kg}$, intraperitoneal injection). Then, atropine of $0.1 \mathrm{mg} / \mathrm{kg}$ was administered to reduce airway secretions by subcutaneous injection. Intraoperative monitoring of adequate anesthesia was done by toe pinching. A core body temperature of $37^{\circ} \mathrm{C}$ was maintained by automatic heating blanket during surgery. After exposing heart, myocardial ischemia (MI) was produced by temporarily exteriorizing the heart via a left thoracic incision and placing a 6-0 silk suture with a slipknot around the left anterior descending coronary artery. After 30 minutes of MI, the slipknot was released and the myocardium was reperfused for 
6 hours (only for cardiac function analysis) or 24 hours (for infarct size determination and other measurements). A sham operation was subjected to the same surgical interventions without performing occlusions (OVS group). Blood and tissue samples were obtained after reperfusion for future analysis.

2.3. Echocardiography. After 6 hours of reperfusion, cardiac function was evaluated using an echocardiography system (Visual Sonics Vevo 2100, VisualSonics, CA) equipped with a $12-\mathrm{MHz}$ linear-array transducer. Two-dimensional (2D) images were obtained in the parasternal long axis view. Left ventricular (LV) ejection fraction (EF) and fractional shortening (FS) were derived by goal-directed, diagnostically driven software. All measurements were made by one observer who was blinded to the identity of the treatments. The values were averaged over five consecutive cardiac cycles.

2.4. Determination of Myocardial Infarct Size. Myocardial infarct size was determined by Evans blue/triphenyltetrazolium chloride (TTC) staining. Briefly, the hearts were removed and perfused with saline on a Langendorff system to wash blood from the coronary vasculature, followed by staining with $1.5 \%$ Evans blue to determine the area at risk. The heart was sliced horizontally into five slices with similar thickness. The slices were incubated in $1.2 \%$ TTC prepared with Tris Buffered Saline (TBS, $\mathrm{pH} 7.8$ ) for $15 \mathrm{~min}$ at $37^{\circ} \mathrm{C}$. Then, viable nonischemic myocardium stained blue with Evans blue staining, while ischemic but viable myocardium stained red with TTC and necrotic myocardium stained pale white. The infarct area (white) and the area at risk (red plus white) from each section were determined using an Alpha EaseFC image analyzer (Alpha Innotech Corporation. CA, USA). Ratios of risk area to left ventricle (RA/LV) and infarct area to risk area (IA/RA) were calculated as percentages.

2.5. Vascular Relaxation Responses. The thoracic aorta from rat was dissected out and carefully removed from adhering adipose and connective tissues. Vessels were then cut into approximately $4 \mathrm{~mm}$ ring segments with special care to reserve the endothelium and mounted into an organ bath (DMT, A/S Inc., Denmark) filled with Krebs solution (composition in mmol/L: $\mathrm{NaCl} 119, \mathrm{KCl} 4.7, \mathrm{KH}_{2} \mathrm{PO}_{4} 1.18$, $\mathrm{MgSO}_{4} 1.17, \mathrm{NaHCO}_{3} 25, \mathrm{CaCl}_{2} 2.5$, EDTA 0.026, and glucose 5.5, $\mathrm{pH} 7.4$ ) at $37^{\circ} \mathrm{C}$ with $95 \% \mathrm{O}_{2}$ and $5 \% \mathrm{CO}_{2}$. The rings were attached to a force transducer and a resting tension of $9.8 \mathrm{mN}$ was maintained throughout the experiment. For endothelium-dependent relaxation responses, vessel rings were preconstricted with noradrenaline (NE, Jinrao amino acid company, Tianjin, China) of $10^{-7} \mathrm{~mol} / \mathrm{L}$. After the plateau was attained, the rings were exposed to different concentrations of acetylcholine (ACh, $10^{-9} \mathrm{~mol} / \mathrm{L}$ to $10^{-5} \mathrm{~mol} / \mathrm{L}$, Sigma, USA) to obtain cumulative concentration-response curves.

2.6. Measurement of Serum Creatine Kinase (CK), Lactate Dehydrogenase (LDH), Estradiol, and Plasma Malondialdehyde (MDA). Blood samples were collected from the right carotid artery. After centrifuging at $1000 \mathrm{~g}$ for $15 \mathrm{~min}$, the supernatant was obtained for various assays. Serum $\mathrm{CK}$ and $\mathrm{LDH}$ as well as plasma MDA levels were assessed according to the manufacturer's instructions by using commercially available kits (Jiancheng Biochemistry Co. Ltd., Nanjing, China). Serum estradiol levels were estimated by radioimmunoassay kit (Beijing North Institute of Biological Technology). Each measurement was performed in duplicate.

2.7. Western Blotting. Briefly, left ventricle of cardiac tissue was homogenized with a homogenizer in TBS buffer and then centrifuged at $8000 \mathrm{bpm}$ for $5 \mathrm{~min}$ at $4^{\circ} \mathrm{C}$. Precipitation was homogenized in tissue lysis buffer $(\mathrm{NaCl} 150 \mathrm{mmol} / \mathrm{L}$; TRIS $25 \mathrm{mmol} / \mathrm{L} ; \mathrm{NaF} 50 \mathrm{mmol} / \mathrm{L} ; \mathrm{Na}_{3} \mathrm{VO}_{4} 1.0 \mathrm{mmol} / \mathrm{L}$; phenylmethylsulfonyl fluoride $1.0 \mathrm{mg} / \mathrm{L}$; aprotinin $1.0 \mathrm{mg} / \mathrm{L}$; leupeptin $10 \mathrm{mg} / \mathrm{L} ; \mathrm{pH} 7.6$ ) and then placed on ice for $50 \mathrm{~min}$. After centrifugation at $12,000 \mathrm{bpm}$ for $10 \mathrm{~min}$ at $4^{\circ} \mathrm{C}$, the supernatants were removed and stored at $-80^{\circ} \mathrm{C}$. Protein concentrations were determined by the BCA method (Pierce Chemical, USA).

Prestained protein marker (New England Biolabs Ltd, Ontario, Canada) and $60 \mu \mathrm{g}$ protein samples were separated by $8 \%$ or $10 \%$ SDS-PAGE. The separated protein was transferred onto a $0.45 \mu \mathrm{M}$ polyvinylidene fluoride membrane (Millipore, USA). After blocking at room temperature in TBS containing $0.2 \%$ Tween 20 (TBS-T) and 5\% nonfat dry milk for $2 \mathrm{~h}$, the membrane was incubated with P85 $\alpha$ (rabbit monoclonal, 1:1000, Cell Signaling Technology Inc., MA, USA), anti-phosphorylation-Akt (Ser473) (rabbit polyclonal, 1:2000, Cell Signaling Technology Inc. MA, USA), anti-Akt (rabbit polyclonal, 1:1000, Cell Signaling Technology Inc., MA, USA), anti-phosphorylation -eNOS (Ser1177) (rabbit polyclonal, 1:5000, Cell Signaling Technology Inc., MA, USA), anti-eNOS (mouse polyclonal, 1:2000, BD Biotechnology Inc., USA), anti-iNOS (rabbit polyclonal, 1:5000, Bioworld Technology Inc., MD, USA), anti-I $\kappa \mathrm{B} \alpha$ (rabbit polyclonal, 1:5000, Stanza Cruz Biotechnology Inc., CA, USA), $\beta$-actin (mouse monoclonal, 1:4000, Sigma-Aldrich, MO, USA), or GAPDH (mouse monoclonal, 1:6000, Kang Cheng, China) in blocking buffer at $4^{\circ} \mathrm{C}$ overnight. Membranes were then washed 3 times in TBS-T buffer, followed by incubation with 1:6000 dilutions of horseradishperoxidase-conjugated anti-rabbit IgG or 1:4000 dilutions of horseradish-peroxidase-conjugated goat anti-mouse IgG (Santa Cruz Biotechnology, CA, USA) at room temperature for $2 \mathrm{~h}$ and washing 3 times in TBS-T. Visualization was carried out using an Enhanced Chemiluminescence (ECL) kit (Thermo Fisher Scientific Inc., IL, USA).

2.8. Measurement of Superoxide Anion Formation. Hearts or $4 \mathrm{~mm}$ vessel rings of thoracic aorta removed from rats were immediately frozen in Tissue-Tek OCT embedding medium (Sakura Finetek, Tokyo, Japan). Then, the samples were cut into 5 - $\mu \mathrm{m}$-thick sections and placed on glass slides. Dihydroethidium (DHE, $2 \mu \mathrm{M}$, Beyotime, China), topically applied to each tissue section, was used to evaluate superoxide levels in situ. After the slides were incubated in a dark chamber at $37^{\circ} \mathrm{C}$ for $30 \mathrm{~min}$, DHE fluorescences were observed by fluorescence microscope (Olympus, Japan). 
TABLE 1: Level of body weight, uterus weight, and serum estradiol after MI/R.

\begin{tabular}{lccc}
\hline & Body weight $(\mathrm{g})$ & Uterus weight $(\mathrm{g})$ & $\begin{array}{c}\text { Serum estradiol } \\
(\mathrm{pg} / \mathrm{mL})\end{array}$ \\
\hline Control & $269.0 \pm 11.0$ & $0.744 \pm 0.062$ & $502.2 \pm 31.5$ \\
OVS & $329.8 \pm 15.1^{\& \&}$ & $0.162 \pm 0.011^{\& \&}$ & $194.4 \pm 25.0^{\& \& 8}$ \\
OVX & $333.9 \pm 12.3$ & $0.157 \pm 0.009$ & $197.5 \pm 23.8$ \\
CMC & $328.8 \pm 11.4$ & $0.171 \pm 0.018$ & $197.3 \pm 21.2$ \\
L-SI & $302.6 \pm 8.1$ & $0.1953 \pm 0.02684$ & $274.8 \pm 22.4$ \\
M-SI & $288.6 \pm 10.3^{\#}$ & $0.2307 \pm 0.03062$ & $300.5 \pm 21.1$ \\
H-SI & $276.0 \pm 8.3^{\# \#}$ & $0.3448 \pm 0.03841^{\#}$ & $341.4 \pm 25.1^{\# \#}$ \\
OVE & $263.0 \pm 7.5^{\# \#}$ & $0.7432 \pm 0.07498^{\# \#}$ & $471.9 \pm 42.5^{\# \#}$ \\
\hline
\end{tabular}

Values are mean \pm SEM, $n=5-8$. Statistical significance: ${ }^{\& \&} P<0.01$ compared with control; ${ }^{\#} P<0.05,{ }^{\#} P<0.01$ compared with CMC.

2.9. Statistical Analysis. All data are expressed as mean \pm SEM deviation and were analyzed by 1-way ANOVA followed by the Bonferroni post host test as appropriate (Stata13.0 software). Values of $P<0.05$ were considered statistically significant.

\section{Results}

3.1. Effect of SI on Uterus Weight, Body Weight, and Serum Levels of Estradiol in Ovariectomized Rats. After ovariectomy, body weight increased significantly, which was consistent to the fact that higher body weight was in postmenopausal women [21]. Rats with SI $(90 \mathrm{mg} / \mathrm{kg} \cdot \mathrm{d}$ and $270 \mathrm{mg} / \mathrm{kg} \cdot \mathrm{d})$ or $\mathrm{E}_{2}(50 \mu \mathrm{g} / \mathrm{kg} \cdot \mathrm{d})$ administration show significant reduction in body weight. Uterine weight, used as a bioassay for estrogens [22], was measured after 4-week treatment (Table 1). Uterus of lighter weight and lower concentration of $\mathrm{E}_{2}$ were present after ovariectomy, which suggested that ovariectomy elicited estradiol deficiency and uterine atrophy (Table 1). After 4 -week treatment, SI $(270 \mathrm{mg} / \mathrm{kg} \cdot \mathrm{d}, \mathrm{H}-\mathrm{SI}$ group $)$ and $17 \beta$ estradiol $(50 \mu \mathrm{g} / \mathrm{kg} \cdot \mathrm{d}$, OVE group) administration increased estradiol level and uterus weight compared with CMC group (Table 1).

3.2. SI Improved Cardiac Function of Hearts with $I / R$ in Ovariectomized Rats. According to the representative 2D echocardiographs after $6 \mathrm{~h}$ perfusion (Figure 2(a)), ejection fraction (EF) and fractional shortening (FS) decreased in OVX and CMC group compared with OVS group. There was an improvement in EF and FS in M-SI and H-SI group compared with CMC group, which reached the level in OVE group (Figures 2(b) and 2(c)).

3.3. SI Decreased the Infarct Size of Hearts with $I / R$ in Ovariectomized Rats. Compared with OVS group, myocardial infarction size was greater in OVX group, suggesting that $30 \mathrm{~min}$ ischemia followed by $24 \mathrm{~h}$ reperfusion resulted in significant myocardium infarct. The infarction size (IS)/AR was significantly smaller in M-SI group and $\mathrm{H}$-SI group than that in CMC group, which was similar to the level of OVE group, suggesting that SI plays a protective role in the heat during I/R in ovariectomized rats (Figure 3).

3.4. SI Decreased Serum CK and LDH after I/R in Ovariectomized Rats. Serum CK and LDH activity was evaluated to assess the extent of myocardial injury after I/R [23, 24]. A significant increase in CK and LDH activity was observed in OVX and CMC group compared with the OVS group. After 4-week treatment, there were lower levels of CK and MDA in $\mathrm{M}-\mathrm{SI}$ and H-SI group compared with the CMC-treated rats, which reached the level in OVE group (Figure 4).

3.5. SI Upregulated Myocardial PI3K/Akt/eNOS Pathway during $I / R$ in Ovariectomized Rats. To elucidate the protective mechanism of SI on myocardial I/R, expressions of PI3K/Akt/eNOS signaling molecules were determined in myocardium. The ovariectomized rats subjected to I/R demonstrated a significant decrease in protein expression of p85 $\alpha$, phosphorylation of Akt (Ser473), and eNOS (Ser1177) compared with OVS group. After 4-week treatment, there were great increases of above protein expressions in $\mathrm{M}$-SI and $\mathrm{H}$-SI groups compared with the CMC-treated rats, which reached the level in OVE group (Figure 5).

3.6. SI Attenuated Oxidative Stress in Myocardium after $I / R$ Injury in Ovariectomized Rats. Level of ROS reflected by the intensity of DHE fluorescence was much higher in the myocardium of OVX group compared with OVS groups. Four-week treatment with SI significantly reduced ROS production in the myocardium compared with the CMC-treated rats, which was similar to that in OVE group (Figure 6(a)). There was also a significant increase in plasma MDA in OVX and CMC group compared with the OVS group. After 4-week treatment, there were lower levels of MDA in M-SI and H-SI groups compared with CMC group, which reached the level in OVE group (Figure 6(b)).

3.7. SI Inhibited iNOS but Enhanced I $\kappa B \alpha$ Expression in Myocardium after $I / R$ Injury in Ovariectomized Rats. There was higher expression of iNOS in OVX group compared with OVS group, and SI treatment significantly decreased it (Figure 6(c)). Meanwhile, the protein of $\mathrm{I} \kappa \mathrm{B} \alpha$ displayed opposite changes. There was lower expression of $\mathrm{I} \kappa \mathrm{B} \alpha$ in OVX group compared with OVS group, and SI treatment significantly enhanced it, which reached the level in OVE group (Figure $6(\mathrm{~d})$ ). All of these results suggested that SI attenuated myocardial oxidative damage after myocardial I/R injury in ovariectomized rats.

3.8. SI Improved the Endothelium-Dependent Relaxation of Thoracic Aortas in Ovariectomized Rats. Endotheliumdependent relaxation of thoracic aortas to acetylcholine was remarkably impaired in ovariectomized rats after I/R injury compared with OVS group (Figure $7(\mathrm{a})$ ). After four-week treatment, SI treated rats showed significant improvement of endothelium-dependent relaxation of thoracic aorta, which was similar to the effect of estradiol in ovariectomized rats (Figure 7(b)). 


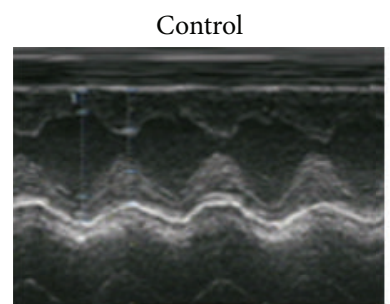

L-SI
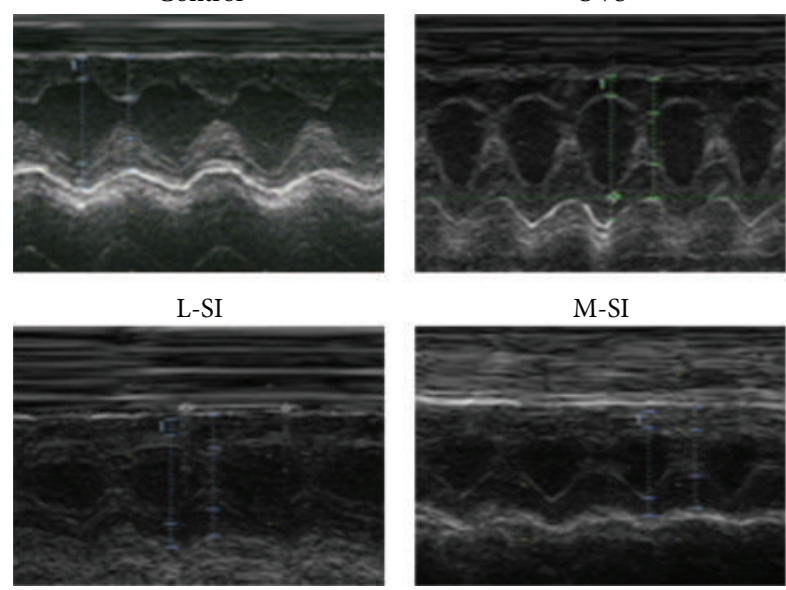

M-SI
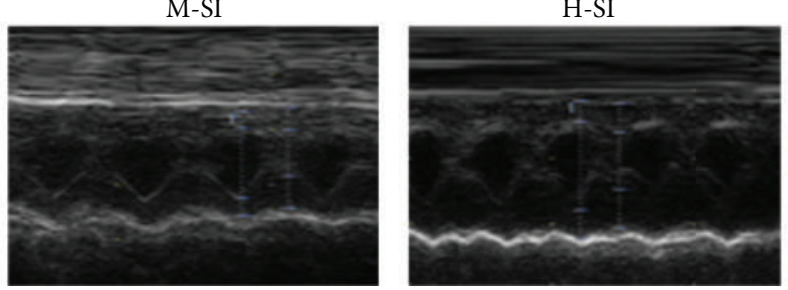

(a)

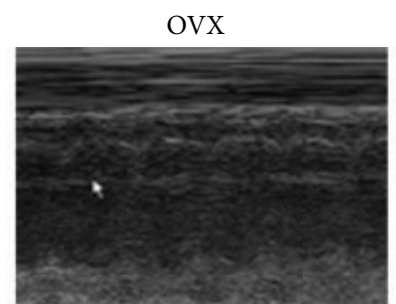

H-SI

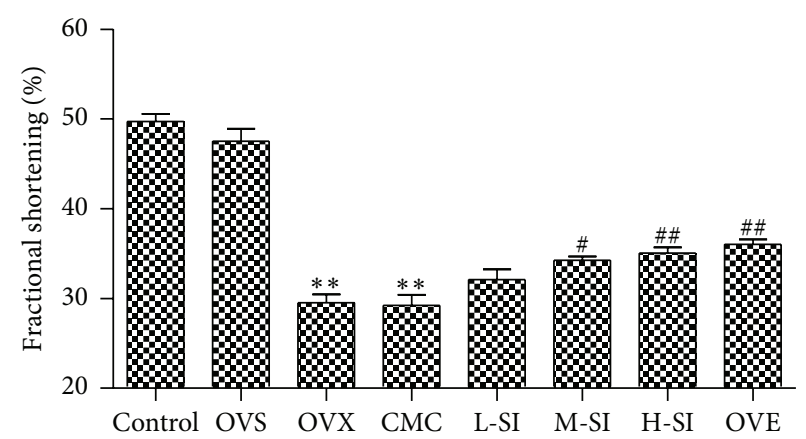

(c)

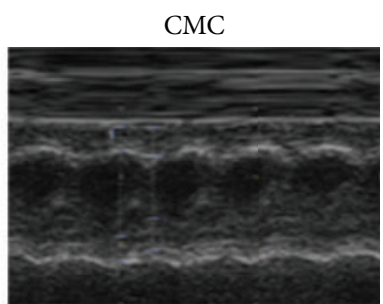

OVE

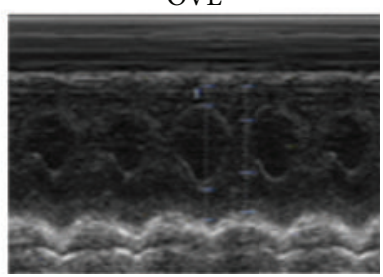

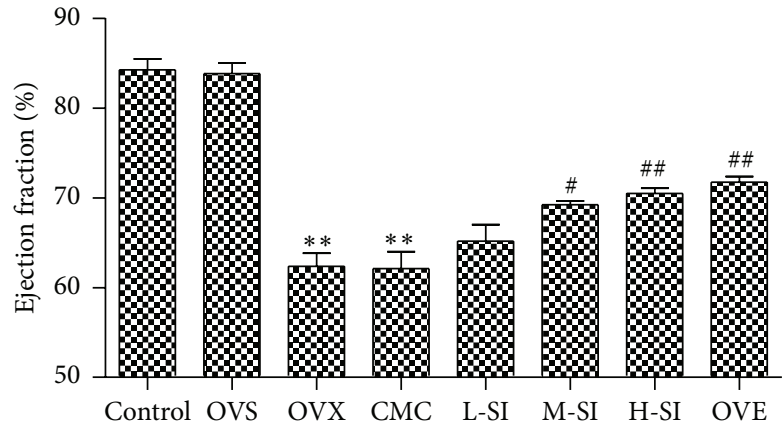

(b)

FIGURE 2: SI improved cardiac function after I/R in ovariectomized rats. (a) Representative echocardiography in each group after $6 \mathrm{~h}$ perfusion. (b) Ejection fraction after $6 \mathrm{~h}$ perfusion. (c) Fractional shortening after $6 \mathrm{~h}$ perfusion. Plots represent the mean \pm SEM, $n=4-6$. Statistical significance: ${ }^{* *} P<0.01$ compared with OVS; ${ }^{\#} P<0.05,{ }^{\# \#} P<0.01$ compared with CMC.

3.9. SI Attenuated Oxidative Stress in Thoracic Aortas after $I / R$ Injury in Ovariectomized Rats. Level of ROS reflected by the intensity of DHE fluorescence was much higher in thoracic aortas of OVX group compared with OVS groups. Four-week treatment with SI significantly reduced ROS production in thoracic aortas, which was similar to that in OVE group (Figure 7(c)).

3.10. SI Suppressed iNOS but Elevated $I \kappa B \alpha$ and PI3K/Akt/ eNOS Expression in Thoracic Aortas after I/R Injury in Ovariectomized Rats. After treatment, SI markedly decreased iNOS expression but increased expression of $\mathrm{I} \kappa \mathrm{B} \alpha$ and $\mathrm{p} 85 \alpha$ and phosphorylation of Akt and eNOS in thoracic aortas (Figures 7(d)-7(h)). Combined with the above results, it was indicated that the improved function of thoracic aortas by SI may be related with inhibition of oxidative stress and improvement of PI3K/Akt/eNOS signaling pathway.

3.11. SI Failed to Decrease the Infarct Size of Hearts with $I / R$ in Ovariectomized Rats If PI3K Was Inhibited. LY294002, a specific inhibitor of the PI3K/Akt pathway, was used to further demonstrate whether PI3K/Akt/eNOS pathway was essential in the attenuating effect of infarct size with $I / R$ in ovariectomized rats. It is worth noting that SI during I/R in ovariectomized rats was not able to reduce the infarction size if PI3K inhibitor was administrated (Figure 8).

\section{Discussion}

As well as we know, after menopause, cardiovascular risk among women becomes progressive because of decreased levels of estrogens $[25,26]$. Estrogen actions are essentially mediated by binding to estrogen receptors [27]. Isoflavone, with similar structure to estrogen, also acts on estrogen receptor to influence the cardiovascular system [28]. Myocardial I/R injury occurs following partial or complete cessation of blood circulation to the myocardium. Since Jennings et al. first described the phenomenon of MI/R injury in 1960 [29], previous researches have been trended to illuminate the mechanisms of MI/R injury and to investigate interventions on cardioprotection [30]. Despite the fact that increasing knowledge has been studied on the protection of MI/R, none of the experimental interventions has proved to be effective in the clinic [31]. All of these highlight the fact that MI/R injury is a complex pathological condition. An effective clinical therapy for $\mathrm{MI} / \mathrm{R}$ remains a great challenge. 


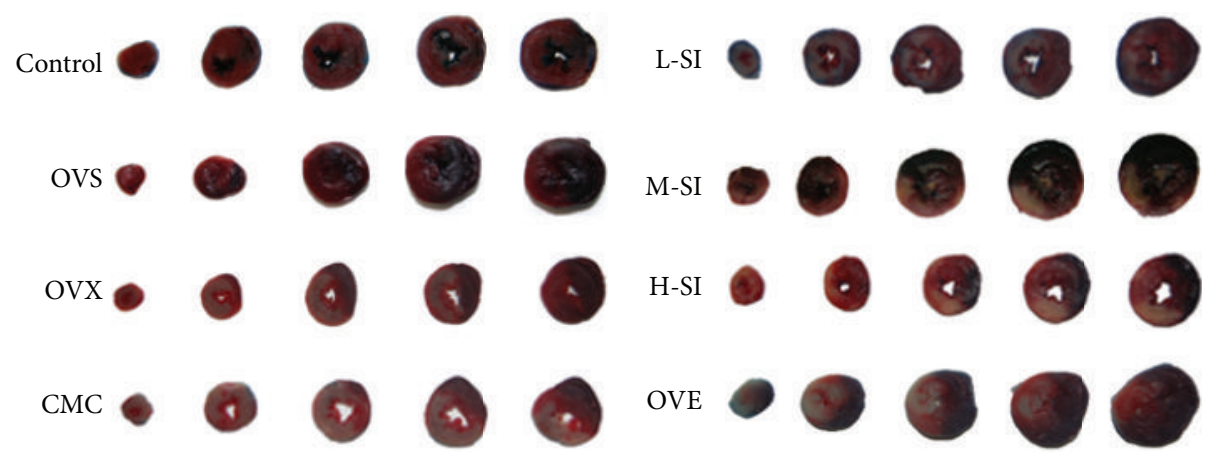

(a)

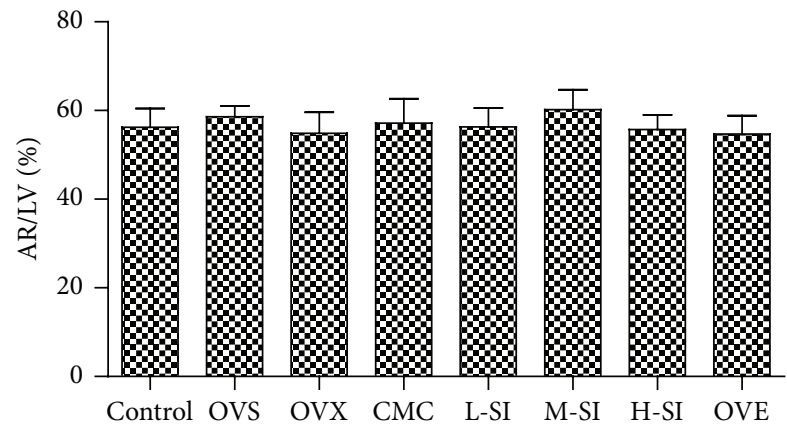

(b)

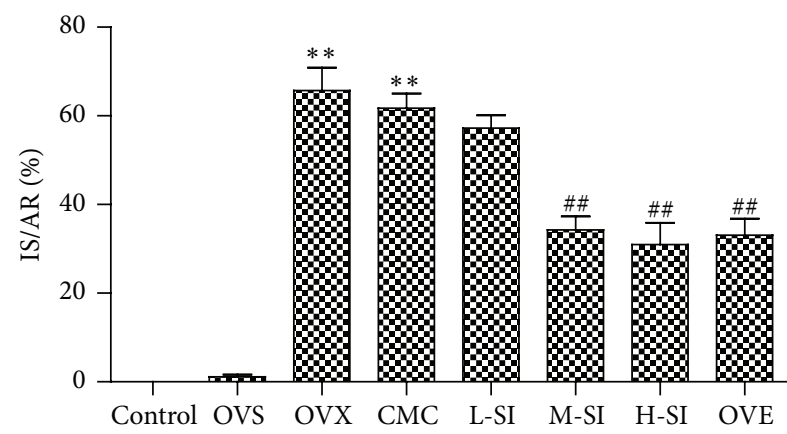

(c)

FiguRE 3: SI decreased MI size after I/R in ovariectomized rats. (a) Representative staining of heart by Evans blue/triphenyltetrazolium chloride (TTC) after $24 \mathrm{~h}$ perfusion. Evans blue-stained areas (blue) indicate nonischemic/reperfused area; TTC stained areas (red staining) indicate ischemic but viable tissue; Evans blue/TTC staining negative areas (white staining) indicate infarcted myocardium; red staining plus white staining indicates area at risk (AR). (b) Ratio of area at risk (AR)/left ventricle (LV) in each group after $24 \mathrm{~h}$ perfusion. (c) Ratio of area of infarction size (IS)/AR after $24 \mathrm{~h}$ perfusion. Plots represent the mean \pm SEM, $n=3-5$. Statistical significance: ${ }^{* *} P<0.01$, compared with OVS; ${ }^{\# \#} P<0.01$ compared with CMC.

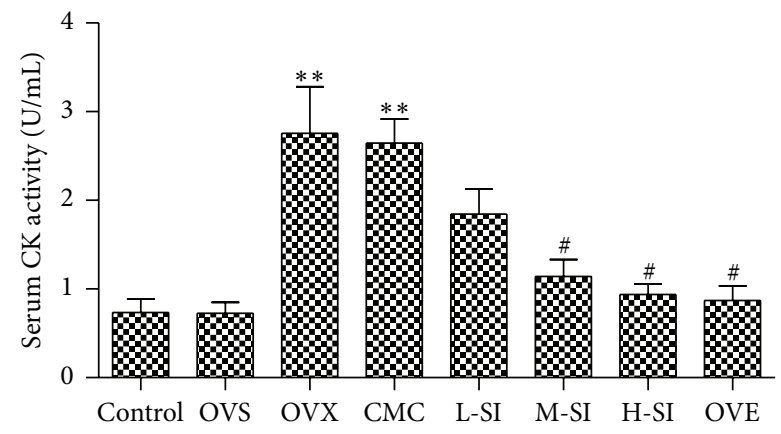

(a)

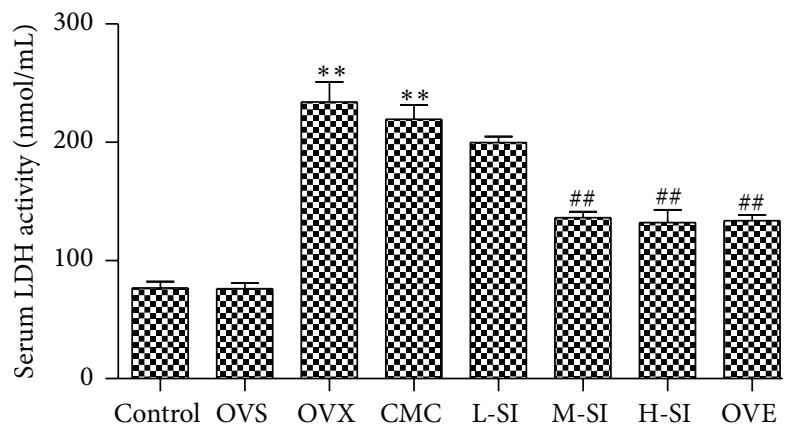

(b)

FIgURE 4: SI decreased serum CK and LDH activity after I/R in ovariectomized rats. (a) Level of serum CK activity. (b) Level of serum LDH activity after $24 \mathrm{~h}$ perfusion. Plots represent the mean \pm SEM, $n=4-6$. Statistical significance: ${ }^{* *} P<0.01$ compared with OVS; ${ }^{*} P<0.05$, ${ }^{\# \#} P<0.01$ compared with CMC.

Several studies have showed that there were apparent gender differences of risk of cardiovascular diseases between men and women [32-34]. This difference might be attributed to the loss of female sex steroid hormones after menopause, but the biological explanations for gender differences in cardiovascular diseases, including myocardial I/R injury, are more complex. In our study, serum estradiol concentration and uterine weight decreased but body weight increased in ovariectomized rats, which imitate the menopause situation in women. Recent studies indicate that sex steroid hormones and their receptors are critical determinants of cardiovascular gender differences [35]. Some other research has focused on the effects of estrogen and estrogen receptors on cardiovascular physiology and disease [36]. Isoflavone, as an analog to estrogen, may act on estrogen receptors [37] and might have potential protection to cardiovascular diseases in 


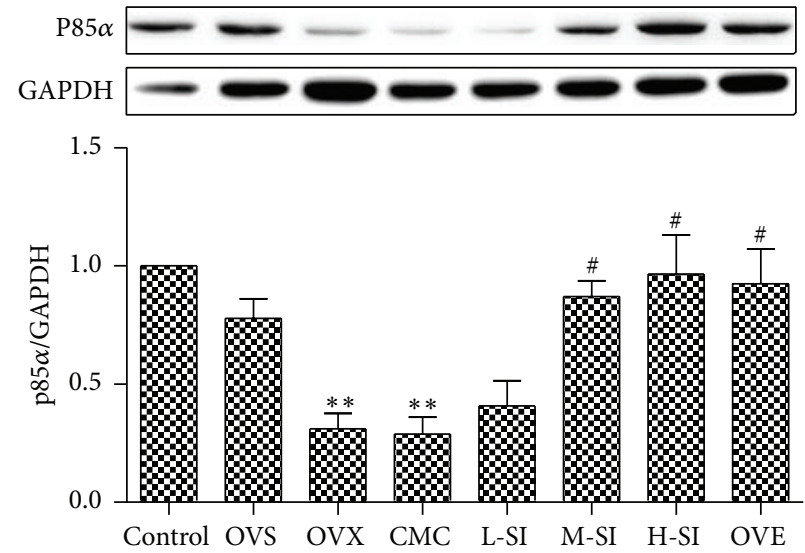

(a)

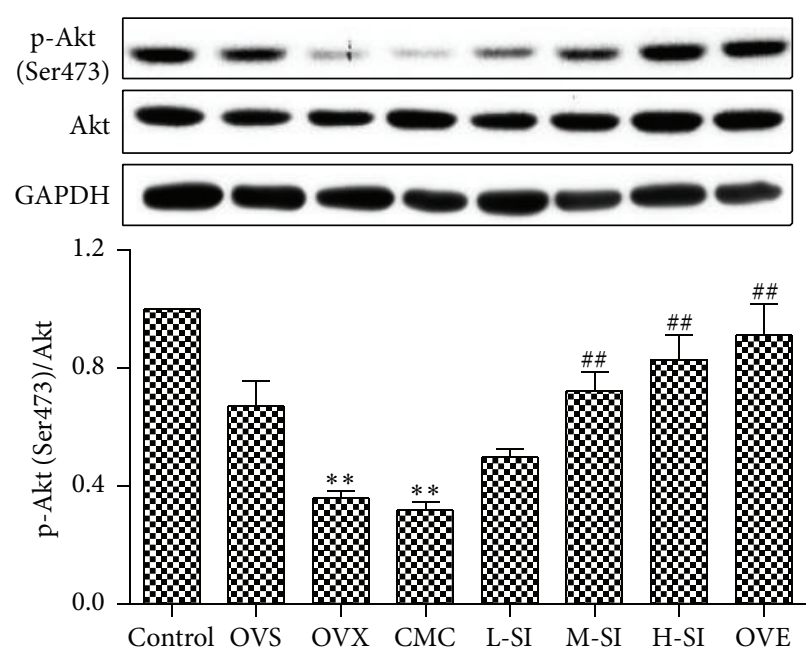

(b)

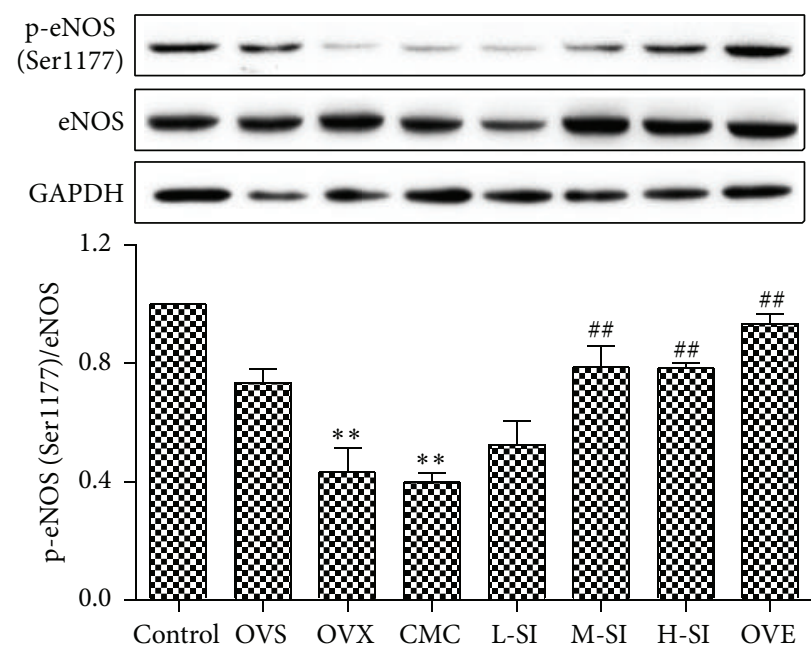

(c)

FIGURE 5: SI increased myocardial PI3K/Akt/eNOS pathway during I/R in ovariectomized rats. Expression of p85 $\alpha$ (a), phosphorylation of Akt (Ser473) (b), and eNOS (Ser1177) (c) with western blotting after $24 \mathrm{~h}$ perfusion. Plots represent the mean \pm SEM, $n=5$-6. Statistical significance: ${ }^{* *} P<0.01$, compared with OVS; ${ }^{\#} P<0.05,{ }^{\# \#} P<0.01$ compared with CMC.

postclimacteric women [38]. A randomized, cross-over soy isoflavone feeding study in 12 healthy premenopausal women for about 100 days found that SI decreased estrogen synthesis [39]. However, our present study suggested that SI administrated for 4 weeks increased serum estradiol level. The discrepancy may be attributed to different treatment durations, different models, different ages, and different methods of measurement or a combination of these factors. Detailed mechanism should be investigated in further studies.

It has been proposed that ROS cause oxidative damage to a variety of cellular components and play an important role in the etiology of MI/R injury [40,41]. Tissue injury mediated by oxygen-derived free radicals might be due to the activation of lipid peroxidation in cellular and subcellular membranes. Lipid peroxides are unstable and decompose to form a series of compounds including reactive carbonyl compounds [42]. Polyunsaturated fatty acid peroxides are able to generate MDA, which is an indicator of lipid peroxidation [43]. Previous study has reported that I/R injury could partly be prevented by a ROS scavenger [44]. After $\mathrm{MI} / \mathrm{R}$ injury, MDA production was increased compared with sham group but isoflavone restored them. Our study also found that isoflavone decreased DHE fluorescence intension and expression of iNOS but increased $\mathrm{I} \kappa \mathrm{B} \alpha$ expression after isoflavone treatment. These findings suggested administration of isoflavone for four weeks before I/R appeared to provide obvious antioxidant effects for attenuating intracellular ROS generation in the myocardium. Accordingly, isoflavone enhanced the cardiac function after $\mathrm{MI} / \mathrm{R}$ in our research, which might be beneficial to protect cardiovascular function in clinic after menopause.

Previous studies have shown conflicting results on the role of ROS on infarct size. A number of studies find that antioxidants or scavengers reduce infarct size during I/R 


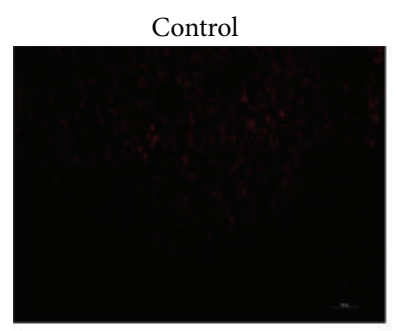

L-SI
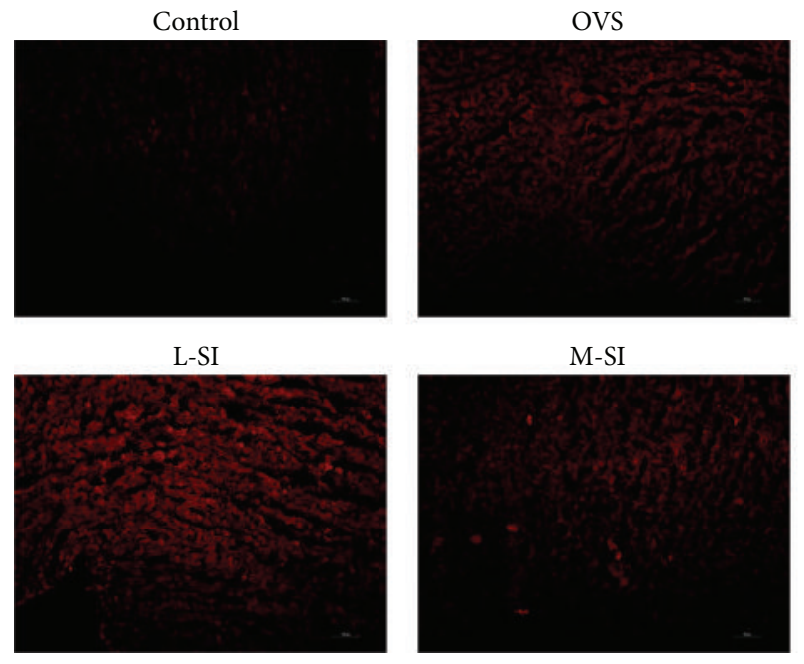

M-SI

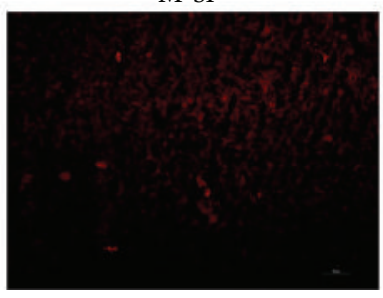

(a)

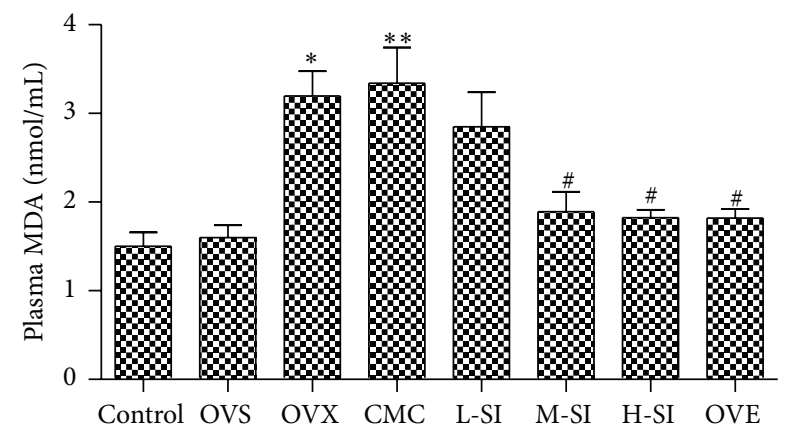

(b)
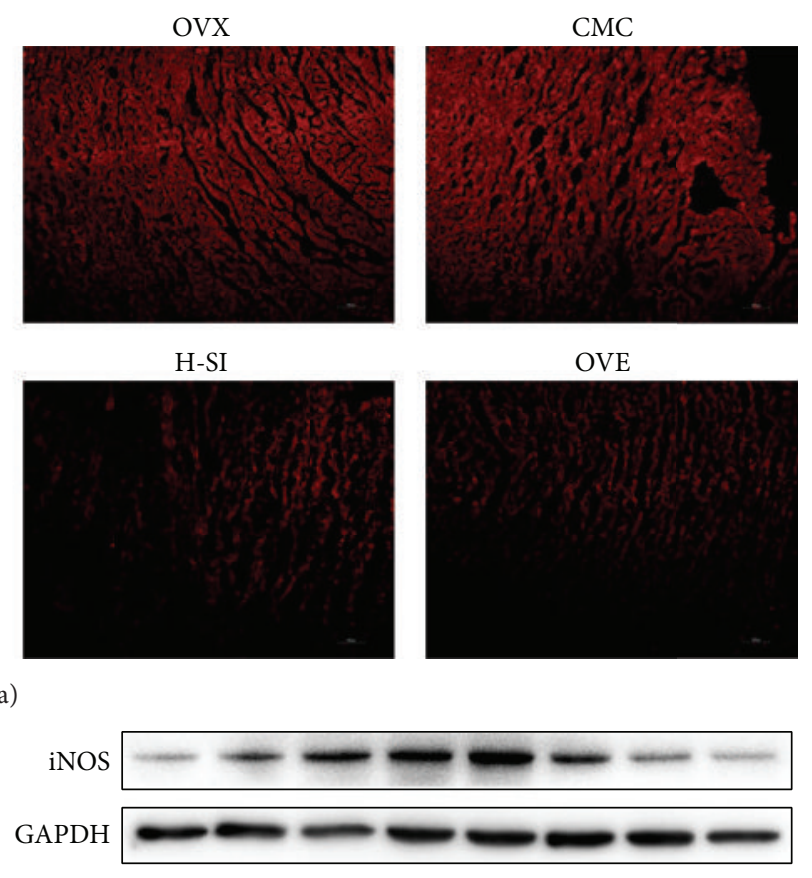

H-SI
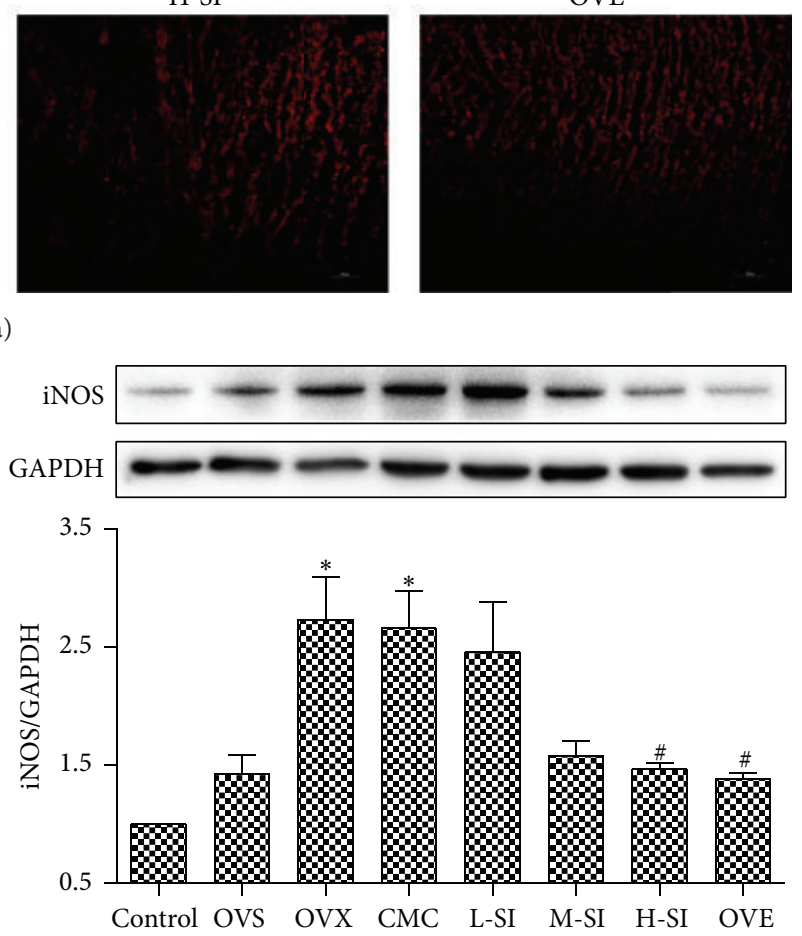

(c)

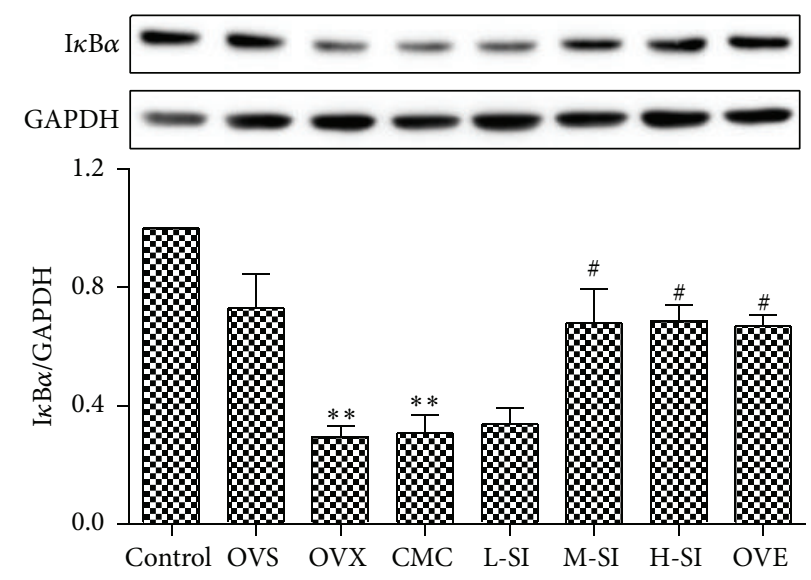

(d)

FIGURE 6: SI decreased myocardial oxidative stress and iNOS expression but increased $\mathrm{I} \kappa \mathrm{B} \alpha$ expression after I/R injury in ovariectomized rats. (a) Dihydroethidium (DHE) fluorescence staining of myocardium. (b) Lever of plasma MDA. ((c) and (d)) Expression of iNOS (c) and $\mathrm{I} \kappa \mathrm{B} \alpha(\mathrm{d})$ in myocardium with western blotting after $24 \mathrm{~h}$ perfusion. Plots represent the mean $\pm \mathrm{SEM}, n=6$. Statistical significance: ${ }^{*} P<0.05$, ${ }^{* *} P<0.01$ compared with OVS; ${ }^{*} P<0.05$ compared with CMC. 

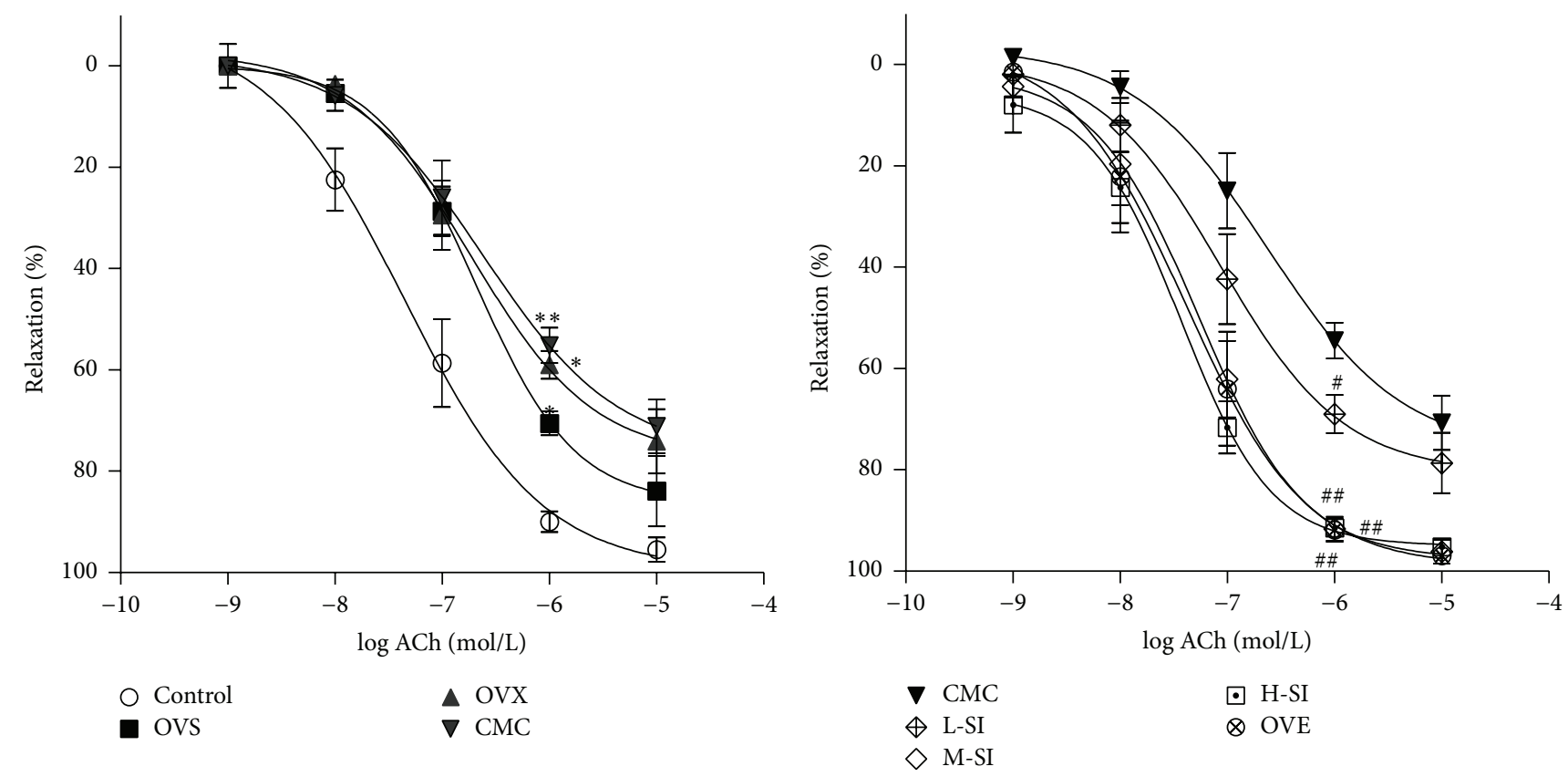

(a)

(b)

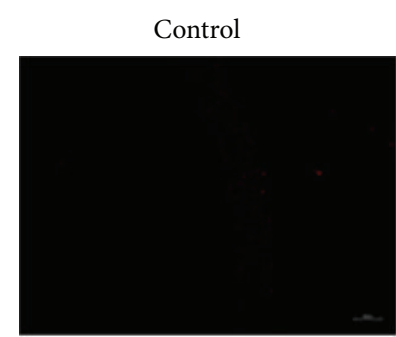

L-SI

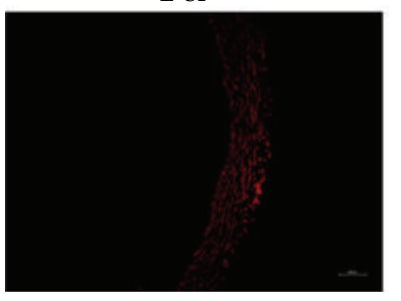

M-SI
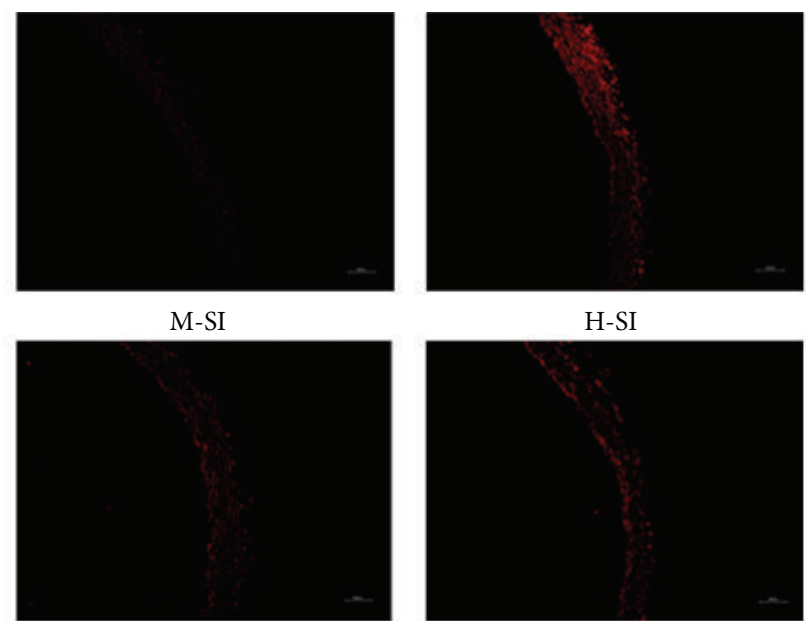

H-SI

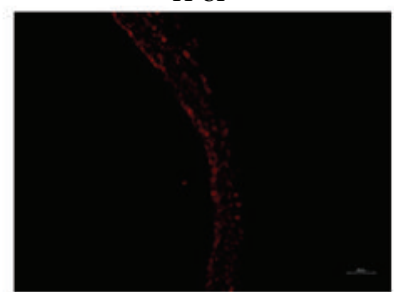

(c)
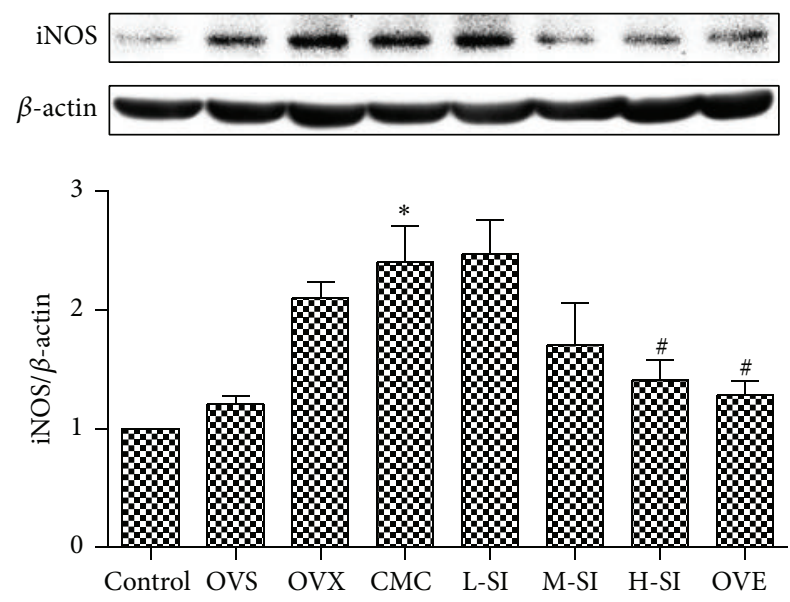

(d)
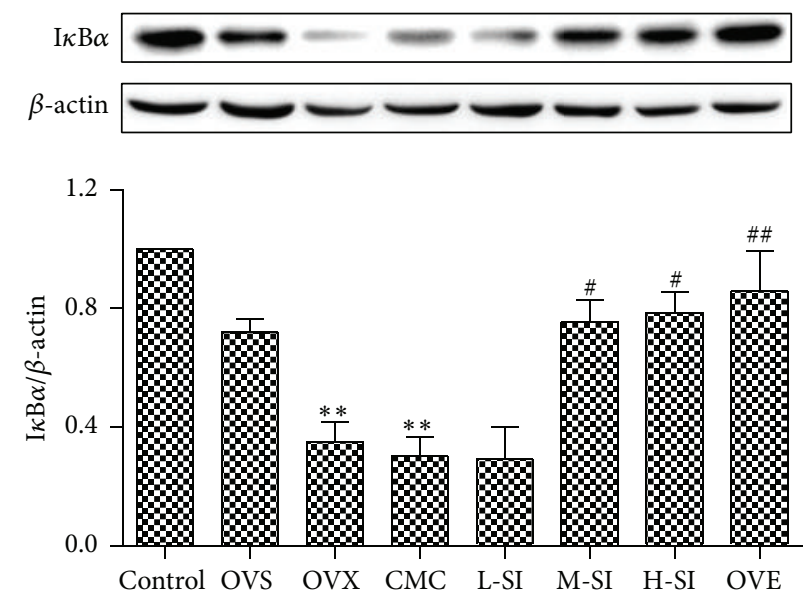

(e)

Figure 7: Continued. 

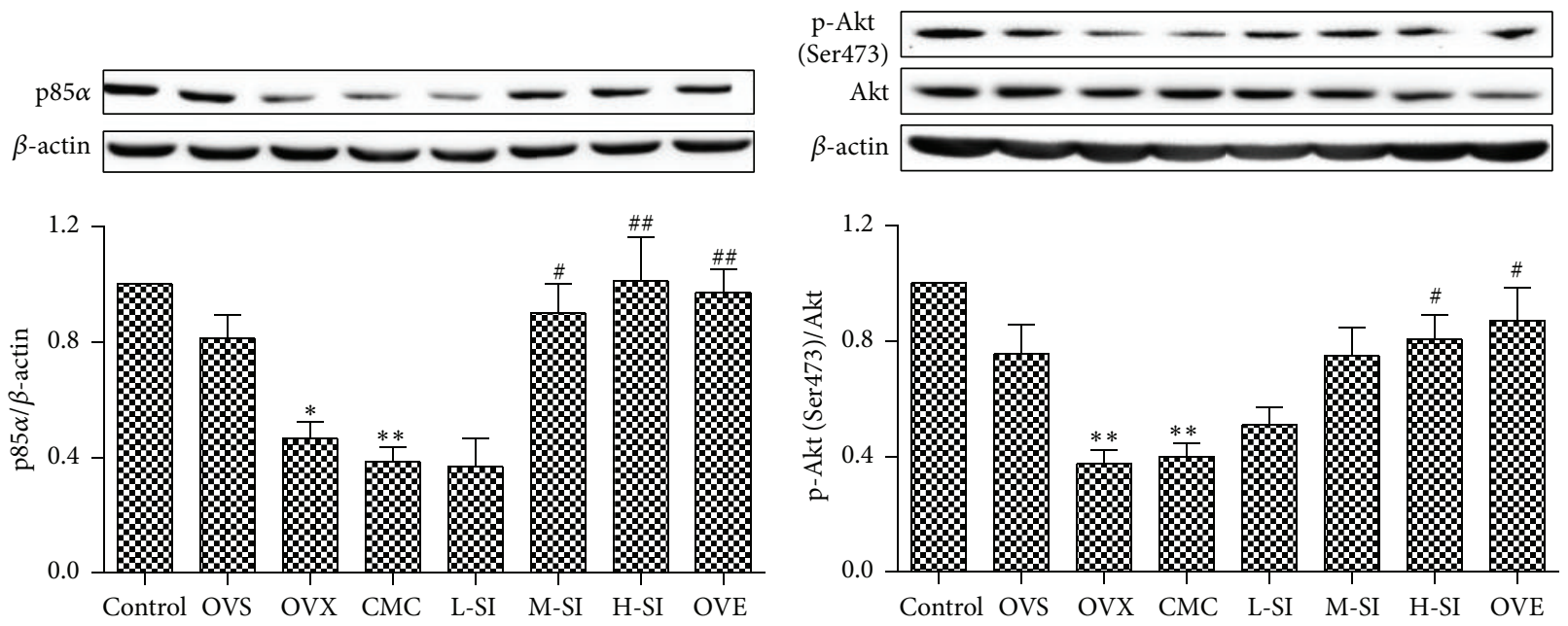

(f)

(g)

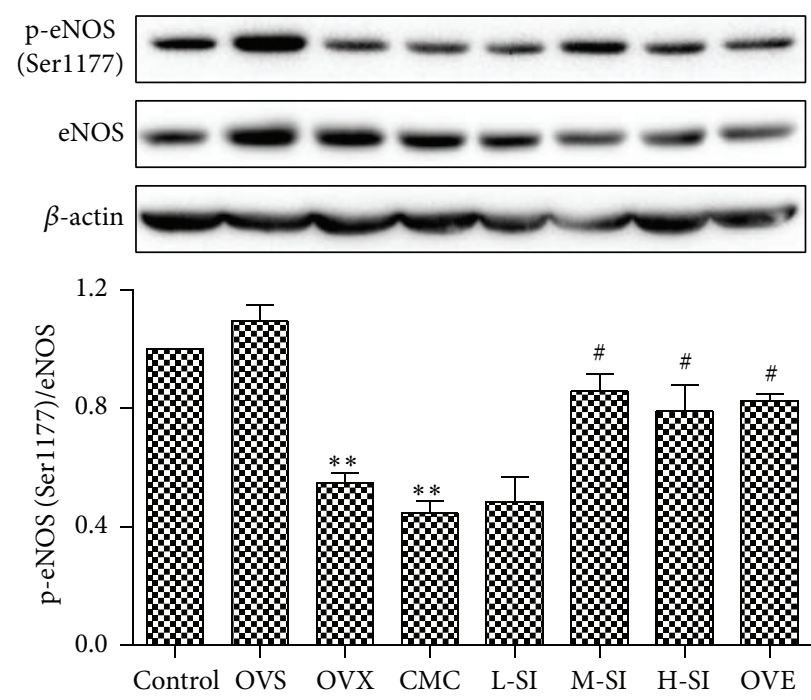

(h)

FIgURE 7: SI improved endothelium-dependent vasorelaxation, decreased oxidative stress and iNOS expression, and increased I $\kappa \mathrm{B} \alpha$ expression and PI3K/Akt/eNOS phosphyration in thoracic aorta in ovariectomized rats. (a and b) Endothelium-dependent vasorelaxation to acetylcholine of precontracted aortic sections was assessed. (c) Dihydroethidium (DHE) fluorescence staining of thoracic aorta. ((d)-(h)) Expression of iNOS (d), I $\kappa \mathrm{B} \alpha$ (e), and p85 $\alpha$ (f), phosphorylation of Akt (Ser473) (g) and eNOS (Ser1177) (h) in thoracic aorta with western blotting after $24 \mathrm{~h}$ perfusion. Plots represent the mean \pm SEM, $n=5-7$. Statistical significance: ${ }^{*} P<0.05,{ }^{* *} P<0.01$ compared with OVS; ${ }^{\#} P<0.05,{ }^{\#} P<0.01$ compared with CMC.

$[45,46]$, while some other studies find no reduction in infarct size $[47,48]$. And some reports suggested that antioxidants could only delay but not prevent manifestations of infarction [49]. These nonconsistent findings may be attributable to the difference in disease courses and drug species or doses. In our study, we found that isoflavone reduced infarct size after MI/R injury in ovariectomized rats accompanied with decreased level of oxidative stress.

On the other hand, a number of recent studies have indicated that "ischemia/reperfusion injury salvage," including $\mathrm{PI} 3 \mathrm{~K}$ and Akt activation, played a vital role in the process of myocardium I/R $[50,51]$. As is reported, one of the major targets of Akt is eNOS, which catalyzes L-arginine to produce nitric oxide (NO) and is pivotal to the cardioprotection in myocardium I/R injury [52]. In our study, we found that expression of P85 $\alpha$, phosphorylation of Akt (Ser473), and eNOS (Ser1177) decreased significantly in ovariectomized rats after $\mathrm{MI} / \mathrm{R}$ injury. After isoflavone treatment, the protein expressions of PI3K/Akt/eNOS signal pathway increased, which might accelerate intracellular signaling transduction and are attributed to a marked anti-I/R injury effect. More importantly, upregulation of PI3KAkt/eNOS signal pathway induced by adequate doses of isoflavone was similar to that induced by $17 \beta$-estradiol supplementary. This action might be responsible for the uniform estrogen receptor, which can activate PI3K related signaling $[53,54]$. It is worth noting that the attenuating effect of SI was unavailable during I/R in ovariectomized rats if LY294002 was administrated. 


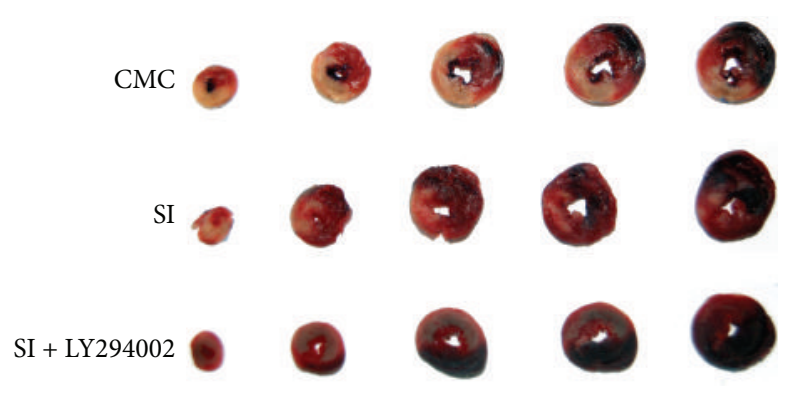

(a)

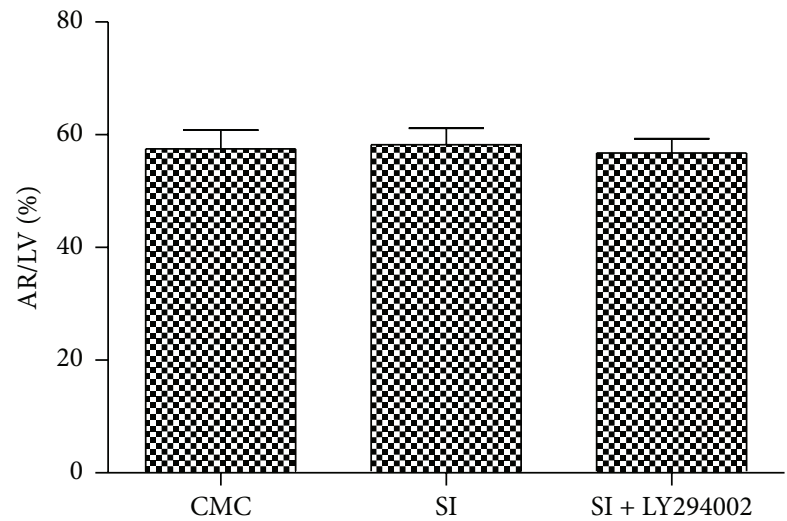

(b)

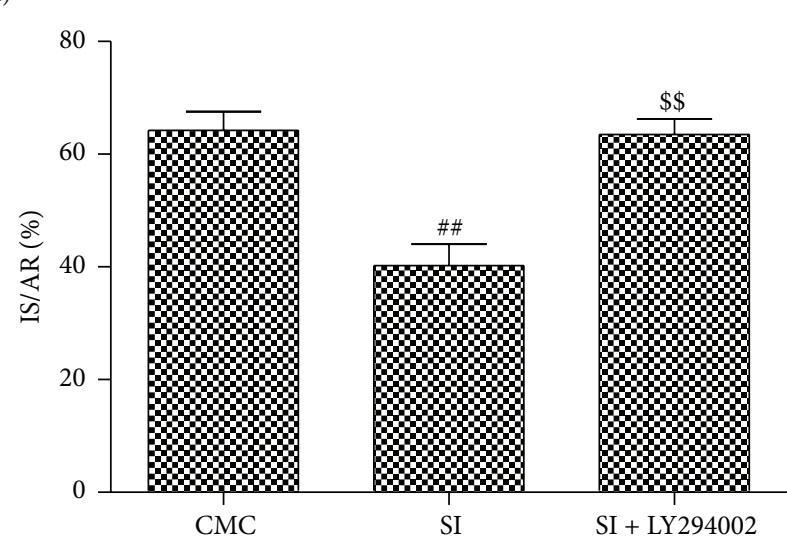

(c)

FIGURE 8: SI failed to decrease the infarct size of hearts with I/R in ovariectomized rats if PI3K was inhibited. One week after ovariectomy, the female SD rats were given 0.5\% CMC (CMC group) or SI of $270 \mathrm{mg} / \mathrm{kg} \cdot \mathrm{d}$ by gavage (SI group). LY294002 (a specific PI3K inhibitor) at dose of $0.3 \mathrm{mg} / \mathrm{kg}$ was intraperitoneally injected immediately after SI was given (SI + LY294002 group). (a) Representative staining of heart by Evans blue/TTC after $24 \mathrm{~h}$ perfusion. (b) Ratio of area at risk (AR)/left ventricle (LV) in each group after $24 \mathrm{~h}$ perfusion. (c) Ratio of area of infarction size (IS)/AR after $24 \mathrm{~h}$ perfusion. Plots represent the mean \pm SEM, $n=4$. Statistical significance: ${ }^{\# \#} P<0.01$, compared with CMC; ${ }^{\$} P<0.01$ compared with SI.

These data suggested that soy isoflavone protects myocardial I/R injury via a PI3K dependent pathway. Meanwhile, inducible NOS (iNOS) and enhanced oxidative stress result in NO uncoupling, and loss of $\mathrm{I} \kappa \mathrm{B}$ elevates inflammation. Both of them exacerbate $M I / R$ injury [18, 55]. And isoflavone inhibited iNOS and but enhanced $\mathrm{I} \kappa \mathrm{B} \alpha$ expression in myocardium after I/R injury.

More intriguingly, cardiac I/R causes not only myocardial but also vascular injury [56]. It has also been proposed that reperfusion induced endothelial dysfunction, characterized by decreased endothelium-dependent vasodilatation [57]. Studies have displayed a potential role of ROS in endothelial dysfunction $[58,59]$. And we found that there was serious oxidative stress in thoracic aortas after I/R injury in ovariectomized rat, which might be an important factor to impair the vascular endothelium. Chronic isoflavone treatment improved endothelium-dependent vasodilation in ovariectomized rats, which might be related to the attenuated effect on oxidative levels. Similar to the effect on myocardium, isoflavone also increased PI3K/Akt/eNOS signal pathway and inhibited iNOS but enhanced $\mathrm{I} \kappa \mathrm{B} \alpha$ expression in thoracic aortas, all of which are helpful to protect vascular functions.
In conclusion, although previous studies have reported beneficial effects of estrogen supplement on women's cardiovascular function, to our knowledge, our data first showed that isoflavone could evoke an enhanced improvement on myocardial I/R injury and vascular relaxation during I/R. This action was shown to be related to the strengthened action of PI3K/Akt/eNOS pathway and attenuated oxidative stress. In brief, our study might raise a possible potential therapeutic of isoflavone for postmenopausal I/R injury and even other cardiovascular diseases in clinic.

\section{Conflict of Interests}

The authors declare that there is no conflict of interests regarding the publication of this paper.

\section{Authors' Contribution}

Yan Tang, Shuangyue Li, Ping Zhang, and Jinbiao Zhu contributed equally to this study. 


\section{Acknowledgments}

This work was supported by Grants from the National Natural Science Foundation of China (Grant nos. 81330004, 81200196, and 81200197), the Collaborative Innovation Center for Cardiovascular Disease Translational Medicine, PAPD, and the Zhang Jiagang Municipal Social Developmental Scientific Research Project (Grant no. e01201200094).

\section{References}

[1] C. J. Lagranha, A. Deschamps, A. Aponte, C. Steenbergen, and E. Murphy, "Sex differences in the phosphorylation of mitochondrial proteins result in reduced production of reactive oxygen species and cardioprotection in females," Circulation Research, vol. 106, no. 11, pp. 1681-1691, 2010.

[2] K. Yahagi, H. R. Davis, E. Arbustini, and R. Virmani, "Sex differences in coronary artery disease: pathological observations," Atherosclerosis, vol. 239, no. 1, pp. 260-267, 2015.

[3] O. S. Ogah, B. A. Davison, K. Sliwa et al., "Gender differences in clinical characteristics and outcome of acute heart failure in sub-Saharan Africa: results of the THESUS-HF study," Clinical Research in Cardiology, vol. 104, no. 5, pp. 481-490, 2015.

[4] J. Sassarini and M. A. Lumsden, "Oestrogen replacement in postmenopausal women," Age and Ageing, vol. 44, no. 4, pp. 551558, 2015.

[5] G. V. Dous, R. Grodman, A. Mornan, P. Otterbeck, and A. Grigos, "Menopausal hormone treatment in postmenopausal women: risks and benefits," Southern Medical Journal, vol. 107, no. 11, pp. 689-695, 2014.

[6] D. Husain, K. Khanna, S. Puri, and M. Haghighizadeh, "Supplementation of soy isoflavones improved sex hormones, blood pressure, and postmenopausal symptoms," Journal of the American College of Nutrition, vol. 34, no. 1, pp. 42-48, 2015.

[7] H.-H. Lu, Y.-M. Wu, W.-T. Chang et al., "Molecular imaging of ischemia and reperfusion in vivo with mitochondrial autofluorescence," Analytical Chemistry, vol. 86, no. 10, pp. 5024-5031, 2014.

[8] T.-T. Li, Y.-S. Zhang, L. He et al., "Inhibition of vascular peroxidase alleviates cardiac dysfunction and apoptosis induced by ischemia-reperfusion," Canadian Journal of Physiology and Pharmacology, vol. 90, no. 7, pp. 851-862, 2012.

[9] R. Rodrigo, M. Libuy, F. Feliú, and D. Hasson, "Oxidative stressrelated biomarkers in essential hypertension and ischemiareperfusion myocardial damage," Disease Markers, vol. 35, no. 6, pp. 773-790, 2013.

[10] R. Tanaka, H. Tsutsui, M. Ohkita, M. Takaoka, T. Yukimura, and Y. Matsumura, "Sex differences in ischemia/reperfusioninduced acute kidney injury are dependent on the renal sympathetic nervous system," European Journal of Pharmacology, vol. 714, no. 1-3, pp. 397-404, 2013.

[11] Á. Prókai, A. Fekete, N. F. Bánki et al., "Renoprotective effect of erythropoietin in rats subjected to ischemia/reperfusion injury: gender differences," Surgery, vol. 150, no. 1, pp. 39-47, 2011.

[12] F. A. Babiker, S. Joseph, and J. Juggi, "The protective effects of 17beta-estradiol against ischemia-reperfusion injury and its effect on pacing postconditioning protection to the heart," Journal of Physiology and Biochemistry, vol. 70, no. 1, pp. 151$162,2014$.

[13] C. Huang, H. Gu, Y. Wang, and M. Wang, "Estrogen-induced SDF-1 production is mediated by estrogen receptor- $\alpha$ in female hearts after acute ischemia and reperfusion," Surgery, vol. 150, no. 2, pp. 197-203, 2011.

[14] S. Hernandez-Resendiz, C. Palma-Flores, S. De Los Santos et al., "Reduction of no-reflow and reperfusion injury with the synthetic 17beta-aminoestrogen compound Prolame is associated with PI3K/Akt/eNOS signaling cascade," Basic Research in Cardiology, vol. 110, no. 2, article 1, 2015.

[15] M. Wang, Y. Wang, B. Weil et al., "Estrogen receptor $\beta$ mediates increased activation of PI3K/Akt signaling and improved myocardial function in female hearts following acute ischemia," The American Journal of Physiology-Regulatory Integrative and Comparative Physiology, vol. 296, no. 4, pp. R972-R978, 2009.

[16] P. Charlagorla, J. Liu, M. Patel, J. I. Rushbrook, and M. Zhang, "Loss of plasma membrane integrity, complement response and formation of reactive oxygen species during early myocardial ischemia/reperfusion," Molecular Immunology, vol. 56, no. 4, pp. 507-512, 2013.

[17] Q. Fan, M. Chen, X. Fang et al., "Aging might augment reactive oxygen species (ROS) formation and affect reactive nitrogen species (RNS) level after myocardial ischemia/reperfusion in both humans and rats," Age, vol. 35, no. 4, pp. 1017-1026, 2013.

[18] J.-I. Suzuki, M. Ogawa, S. Muto et al., "Novel I $\kappa$ B kinase inhibitors for treatment of nuclear factor- $\kappa \mathrm{B}$-related diseases," Expert Opinion on Investigational Drugs, vol. 20, no. 3, pp. 395405, 2011.

[19] M. Shahnazari, B. R. Martin, L. L. Legette, P. J. Lachcik, J. Welch, and C. M. Weaver, "Diet calcium level but not calcium supplement particle size affects bone density and mechanical properties in ovariectomized rats," The Journal of Nutrition, vol. 139, no. 7, pp. 1308-1314, 2009.

[20] M.-C. Toufektsian, M. De Lorgeril, N. Nagy et al., "Chronic dietary intake of plant-derived anthocyanins protects the rat heart against ischemia-reperfusion injury," Journal of Nutrition, vol. 138, no. 4, pp. 747-752, 2008.

[21] V. Mpalaris, P. Anagnostis, D. G. Goulis, and I. Iakovou, "Complex association between body weight and fracture risk in postmenopausal women," Obesity Reviews, vol. 16, no. 3, pp. 225-233, 2015.

[22] V. T. Politano, D. McGinty, E. M. Lewis et al., "Uterotrophic assay of percutaneous lavender oil in immature female rats," International Journal of Toxicology, vol. 32, no. 2, pp. 123-129, 2013.

[23] H. Inafuku, Y. Kuniyoshi, S. Yamashiro et al., "Determination of oxidative stress and cardiac dysfunction after ischemia/reperfusion injury in isolated rat hearts," Annals of Thoracic and Cardiovascular Surgery, vol. 19, no. 3, pp. 186-194, 2013.

[24] X. Yang, J. Yang, J. Hu, X. Li, X. Zhang, and Z. Li, “Apigenin attenuates myocardial ischemia/reperfusion injury via the inactivation of p38 mitogenactivated protein kinase," Molecular Medicine Reports, vol. 12, no. 5, pp. 6873-6878, 2015.

[25] M. Canonico, "Hormone therapy and hemostasis among postmenopausal women: a review," Menopause, vol. 21, no. 7, pp. 753-762, 2014.

[26] R. J. Baber, "East is east and West is west: perspectives on the menopause in Asia and the West," Climacteric, vol. 17, no. 1, pp. 23-28, 2014.

[27] L. F. Shapiro and K. Freeman, "The relationship between estrogen, estrogen receptors and periodontal disease in adult wome ," The Journal of the Michigan Dental Association, vol. 96, no. 11, pp. 40-44, 2014. 
[28] M. Messina, "Soy foods, isoflavones, and the health of postmenopausal women," The American Journal of Clinical Nutrition, vol. 100, no. 1, pp. 423S-430S, 2014.

[29] R. B. Jennings, H. M. Sommers, G. A. Smyth, H. A. Flack, and H. Linn, "Myocardial necrosis induced by temporary occlusion of a coronary artery in the dog," Archives of Pathology, vol. 70, pp. 68-78, 1960.

[30] O. M. Duicu, D. Angoulvant, and D. M. Muntean, "Cardioprotection against myocardial reperfusion injury: successes, failures, and perspectives," Canadian Journal of Physiology and Pharmacology, vol. 91, no. 8, pp. 657-662, 2013.

[31] R. S. V. Heide and C. Steenbergen, "Cardioprotection and myocardial reperfusion: pitfalls to clinical application," Circulation Research, vol. 113, no. 4, pp. 464-477, 2013.

[32] H. Bălan and L. Popescu, "'Gender specific medicine’: a focus on gender-differences in hypertension," Romanian Journal of Internal Medicine, vol. 52, no. 3, pp. 129-141, 2014.

[33] M. Izadnegahdar, C. Norris, P. Kaul, L. Pilote, and K. H. Humphries, "Basis for sex-dependent outcomes in acute coronary syndrome," Canadian Journal of Cardiology, vol. 30, no. 7, pp. 713-720, 2014.

[34] J. R. Bell, G. B. Bernasochi, U. Varma, A. J. A. Raaijmakers, and L. M. D. Delbridge, "Sex and sex hormones in cardiac stress-mechanistic insights," Journal of Steroid Biochemistry and Molecular Biology, vol. 137, pp. 124-135, 2013.

[35] S. S. Bassuk and J. E. Manson, "Menopausal hormone therapy and cardiovascular disease risk: utility of biomarkers and clinical factors for risk stratification," Clinical Chemistry, vol. 60, no. 1, pp. 68-77, 2014.

[36] A. A. Knowlton and D. H. Korzick, "Estrogen and the female heart," Molecular and Cellular Endocrinology, vol. 389, no. 1-2, pp. 31-39, 2014.

[37] R. Simons, H. Gruppen, T. F. H. Bovee, M. A. Verbruggen, and J.-P. Vincken, "Prenylated isoflavonoids from plants as selective estrogen receptor modulators (phytoSERMs)," Food and Function, vol. 3, no. 8, pp. 810-827, 2012.

[38] A. Kozłowska and D. Szostak-Wegierek, "Flavonoids-food sources and health benefits," Roczniki Państwowego Zakładu Higieny, vol. 65, no. 2, pp. 79-85, 2014.

[39] X. Xu, A. M. Duncan, B. E. Merz, and M. S. Kurzer, "Effects of soy isoflavones on estrogen and phytoestrogen metabolism in premenopausal women," Cancer Epidemiology Biomarkers and Prevention, vol. 7, no. 12, pp. 1101-1108, 1998.

[40] V. Braunersreuther and V. Jaquet, "Reactive oxygen species in myocardial reperfusion injury: from physiopathology to therapeutic approaches," Current Pharmaceutical Biotechnology, vol. 13, no. 1, pp. 97-114, 2012.

[41] F. Tullio, C. Angotti, M.-G. Perrelli, C. Penna, and P. Pagliaro, "Redox balance and cardioprotection," Basic Research in Cardiology, vol. 108, no. 6, article 392, 2013.

[42] J. Mano, "Reactive carbonyl species: their production from lipid peroxides, action in environmental stress, and the detoxification mechanism," Plant Physiology and Biochemistry, vol. 59, pp. 9097, 2012.

[43] E. Ho, K. Karimi Galougahi, C.-C. Liu, R. Bhindi, and G. A. Figtree, "Biological markers of oxidative stress: applications to cardiovascular research and practice," Redox Biology, vol. 1, no. 1, pp. 483-491, 2013.
[44] C. D. Garciarena, J. C. Fantinelli, C. I. Caldiz et al., "Myocardial reperfusion injury: reactive oxygen species vs. NHE-1 reactivation," Cellular Physiology and Biochemistry, vol. 27, no. 1, pp. 1322, 2011.

[45] M. Mokni, S. Hamlaoui, I. Karkouch et al., "Resveratrol provides cardioprotection after ischemia/reperfusion injury via modulation of antioxidant enzyme activities," Iranian Journal of Pharmaceutical Research, vol. 12, no. 4, pp. 867-875, 2013.

[46] J. Jiang, X. Yuan, T. Wang et al., "Antioxidative and cardioprotective effects of total flavonoids extracted from Dracocephalum moldavica L. against acute ischemia/reperfusioninduced myocardial injury in isolated rat heart," Cardiovascular Toxicology, vol. 14, no. 1, pp. 74-82, 2014.

[47] J. Vanhaecke, F. Van De Werf, A. Ronaszeki, W. Flameng, E. Lesaffre, and H. De Geest, "Effect of superoxide dismutase on infarct size and postischemic recovery of myocardial contractility and metabolism in dogs," Journal of the American College of Cardiology, vol. 18, no. 1, pp. 224-230, 1991.

[48] J. Nejima, D. R. Knight, J. T. Fallon et al., "Superoxide dismutase reduces reperfusion arrhythmias but fails to salvage regional function or myocardium at risk in conscious dogs," Circulation, vol. 79, no. 1, pp. 143-153, 1989.

[49] E. Murphy and C. Steenbergen, "Mechanisms underlying acute protection from cardiac ischemia-reperfusion injury," Physiological Reviews, vol. 88, no. 2, pp. 581-609, 2008.

[50] A. Špániková, M. Ivanová, J. Matejíková, T. Ravingerová, and M. Barančík, "Influence of ischemia/reperfusion and modulation of PI3K/Akt kinase pathway on matrix metalloproteinase-2 in rat hearts," General Physiology and Biophysics, vol. 29, no. 1, pp. 31-40, 2010.

[51] K. Chen, G. Li, F. Geng et al., "Berberine reduces ischemia/ reperfusion-induced myocardial apoptosis via activating AMPK and PI3K-Akt signaling in diabetic rats," Apoptosis, vol. 19, no. 6, pp. 946-957, 2014.

[52] L. Rochette, J. Lorin, M. Zeller et al., "Nitric oxide synthase inhibition and oxidative stress in cardiovascular diseases: possible therapeutic targets?" Pharmacology and Therapeutics, vol. 140, no. 3, pp. 239-257, 2013.

[53] J. Chen and L. Sun, "Formononetin-induced apoptosis by activation of Ras/p38 mitogen-activated protein kinase in estrogen receptor-positive human breast cancer cells," Hormone and Metabolic Research, vol. 44, no. 13, pp. 943-948, 2012.

[54] S. M. R. Rosa Lima, B. F. A. Bernardo, S. S. Yamada, B. F. Reis, G. M. D. Da Silva, and M. A. Longo Galvão, "Effects of Glycine max (L.) Merr. soy isoflavone vaginal gel on epithelium morphology and estrogen receptor expression in postmenopausal women: a 12-week, randomized, double-blind, placebo-controlled trial," Maturitas, vol. 78, no. 3, pp. 205-211, 2014.

[55] H. Otani, "The role of nitric oxide in myocardial repair and remodeling," Antioxidants \& Redox Signaling, vol. 11, no. 8, pp. 1913-1928, 2009.

[56] V. Sharma, M. T. Kearney, S. M. Davidson, and D. M. Yellon, "Endothelial insulin resistance protects the heart against prolonged ischemia-reperfusion injury but does not prevent insulin transport across the endothelium in a mouse langendorff model," Journal of Cardiovascular Pharmacology and Therapeutics, vol. 19, no. 6, pp. 586-591, 2014.

[57] M. Zhao, X. He, W. G. Wier et al., "Endothelial dysfunction in rat mesenteric artery after regional cardiac ischaemiareperfusion," Experimental Physiology, vol. 97, no. 1, pp. 70-79, 2012. 
[58] L. C. Sanchez-Aranguren, C. E. Prada, C. E. Riano-Medina, and M. Lopez, "Endothelial dysfunction and preeclampsia: role of oxidative stress," Frontiers in Physiology, vol. 5, article 372, 2014.

[59] Y. Higashi, T. Maruhashi, K. Noma, and Y. Kihara, "Oxidative stress and endothelial dysfunction: clinical evidence and therapeutic implications," Trends in Cardiovascular Medicine, vol. 24, no. 4, pp. 165-169, 2014. 


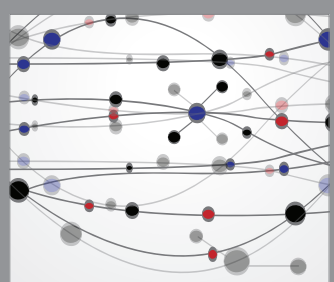

The Scientific World Journal
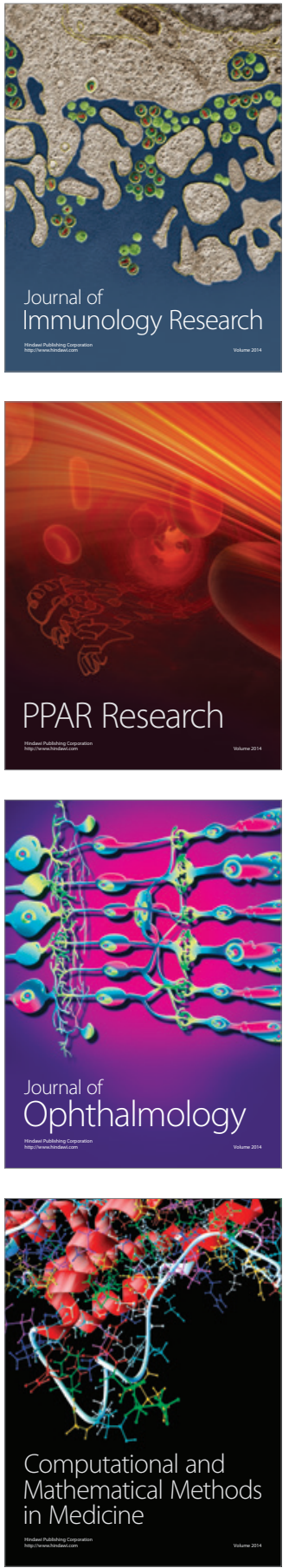

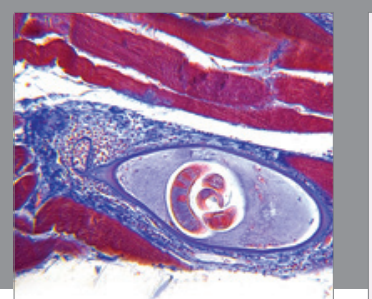

Gastroenterology Research and Practice

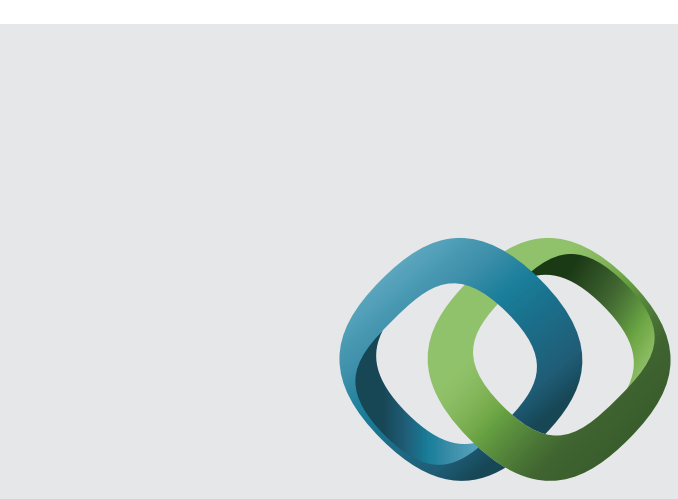

\section{Hindawi}

Submit your manuscripts at

http://www.hindawi.com
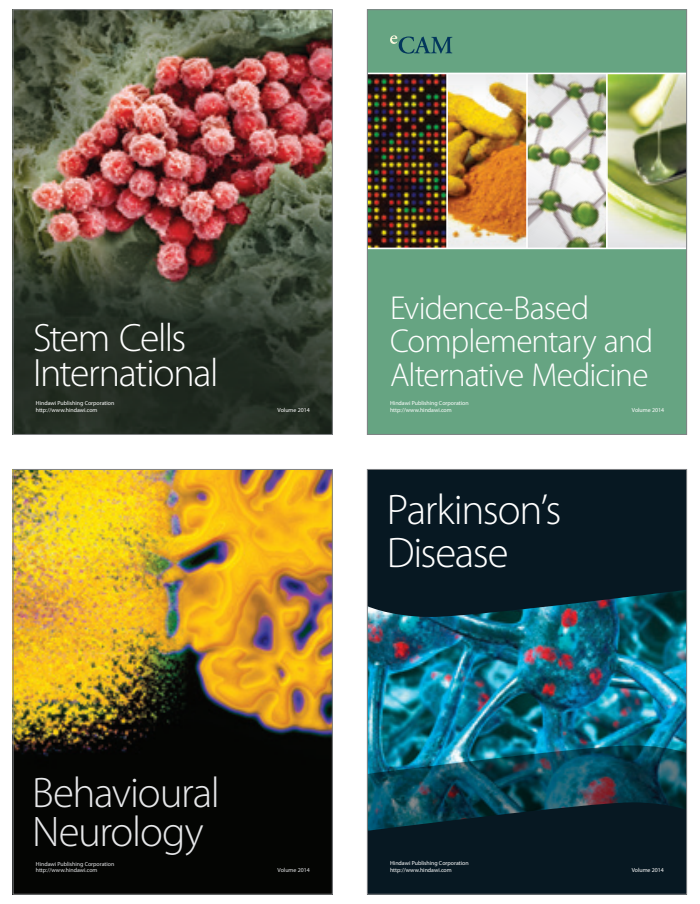
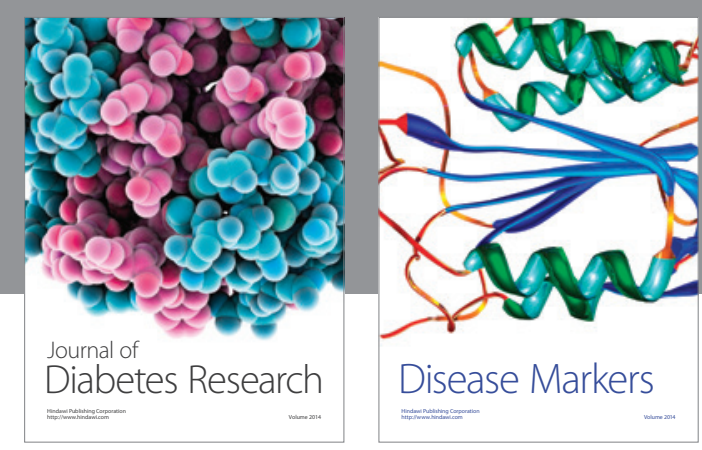

Disease Markers
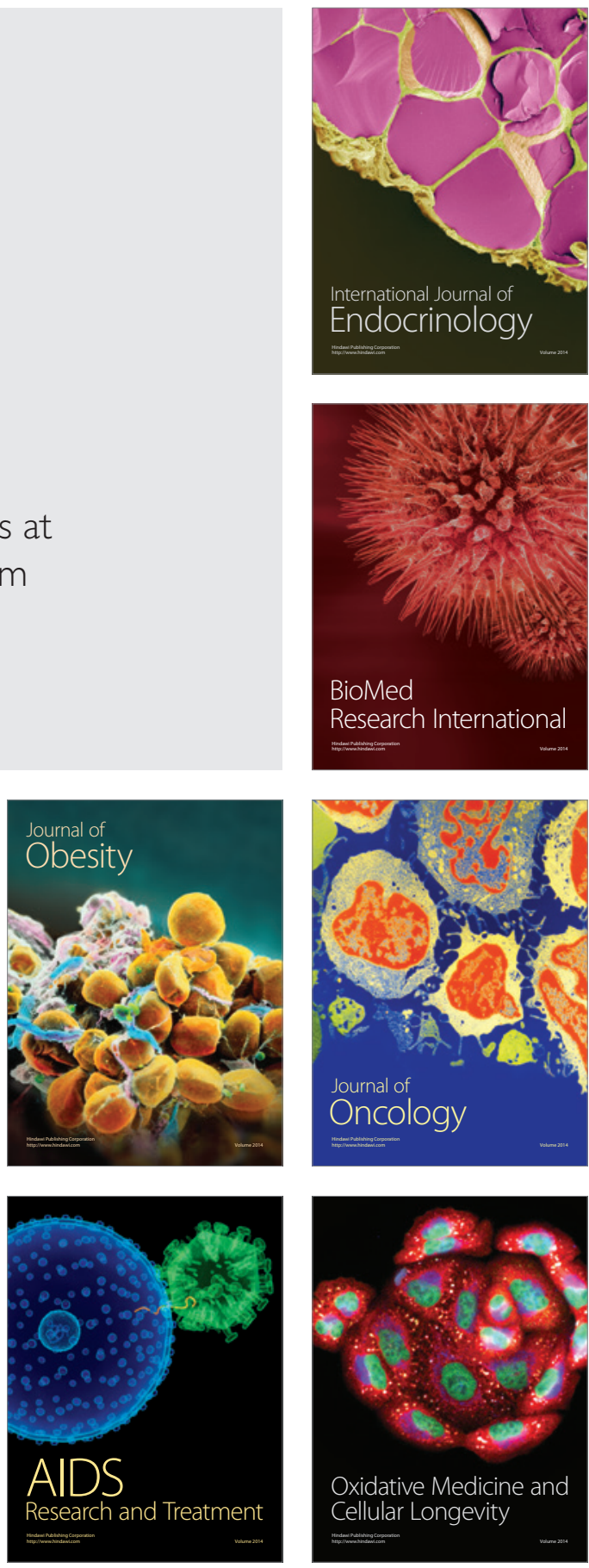